\title{
Disposições técnicas e diretrizes para projeto de habitações sociais evolutivas
}

\author{
Technical recommendations and guidelines for designing \\ adaptable low-income houses
}

\section{Douglas Queiroz Brandão}

\section{Resumo \\ $\mathbf{P}$}

rojetar a habitação, considerando tão somente as necessidades da fase de construção e da ocupação inicial, resulta, com frequência, em dificuldades e custos adicionais para adaptar posteriormente a residência de forma a atender mudanças nos requisitos de seus usuários. Este trabalho destaca a importância da consideração da flexibilidade de espaço, de materiais e de componentes em projetos habitacionais de interesse social (HIS). O objetivo é propor, à luz da literatura especializada e dos problemas constatados na prática, um conjunto de diretrizes para projeto que permitam a adaptação facilitada e harmoniosa da moradia ao longo de sua vida útil. A tipologia enfocada é a habitação unifamiliar, particularmente aquela edificada isoladamente no lote. A pesquisa foi desenvolvida com base na observação de uma amostra de habitações do Estado de Mato Grosso, entre 2003 a 2006, sendo dividida em duas etapas. Na primeira etapa, foram levantadas e analisadas as modificações espontâneas realizadas pelos usuários, mostrando as alterações típicas realizadas e os problemas mais comuns na ampliação destas residências. Na segunda, foram propostas disposições técnicas, relacionando estas às estratégias e aos princípios da flexibilidade, de forma a tornar as casas mais adaptáveis. O artigo também buscou refletir sobre as práticas correntes de projeto e produção dos empreendimentos de HIS, visando reforçar a importância do conceito de habitação evolutiva e defender uma maior abertura a novos desenhos que permitam maior apropriação do espaço doméstico por seus ocupantes.

Palavras-chave: Habitação de interesse social. Projeto habitacional. Habitação evolutiva. Flexibilidade arquitetônica. Sistemas construtivos. Adaptabilidade.

\begin{abstract}
The practice of designing housing projects considering only the needs of the construction phase and the first occupation of the dwellings often leads to difficulties and additional costs in adapting the house in order to fulfill changing user requirements. This article highlights the importance of including flexibility in terms of space, building materials and components in the design of social housing projects. The aim of the study is to propose a set of technical recommendations, based on the literature and on problems identified in practice, in order to allow easy and harmonious changes in dwellings in the course of its life cycle. The focus of this study is the typology of detached houses for single families. This study was based on the observation of a sample of houses from the state of Mato Grosso, between 2003 and 2006, and was divided into two phases. In the first phase, the changes and extensions made by the users were classified and analyzed in order to identify typical changes and the most common problems found in the extension of those houses. In the second phase, the study proposed some technical recommendations, which were connected to a set of flexibility strategies and principles that promote adaptability in house building. The study also aimed to reflect on existing design and production practices in social housing projects in Brazil, emphasizing the importance of the concept of adaptable housing, and suggest greater openness to new designs that allow a stronger appropriation of the dwelling by the users.
\end{abstract}

Keywords: Low-incoming housing. Housing design. Adaptable houses. Architectural flexibility. Construction systems. Adaptability.
Recebido em 20/10/10 Aceito em 13/05/11

Douglas Queiroz Bran Faculdade de Arquitetura, Engenharia Universidade Federal de Mato Grosso Av. Fernando Correa da Costa, 2367 Cuiabá - MT - Brasil Tel.: (65) 3615-8972 E-mail: dbrandao@ufmt.br 


\section{Habitação evolutiva}

A qualidade da habitação manifesta-se por atributos físicos e psicológicos. Pedro (2000) propõe sete grupos de variáveis com o objetivo de avaliar a qualidade habitacional. São exigências: de habitabilidade, de segurança, de uso (adequação espacial-funcional, articulação e personalização), estéticas e de economia. A personalização, que é visualizada por espaços que permitem apropriação e adaptação, é a característica focalizada no presente artigo.

Destaca-se a importância da consideração da flexibilidade arquitetônica na habitação de interesse social, sendo a tipologia enfocada a moradia unifamiliar edificada de forma isolada no lote. O objetivo do artigo é organizar um conjunto de diretrizes para projeto que possibilite a adaptação facilitada, adequada e harmoniosa da moradia ao longo de sua vida útil. O estudo baseou-se na literatura especializada e no levantamento de inadequações e dificuldades observadas em dois conjuntos habitacionais e quatro casas experimentais, em cidades do interior do Estado de Mato Grosso. Ao final do trabalho as diretrizes obtidas são analisadas ao mesmo tempo em que se questiona o modelo de desenho típico dos espaços domésticos.

Uma habitação é considerada polivalente ou evolutiva quando, dada a maneira como foram concebidos os seus espaços, permite alterar os usos dentro dela, ocupá-la de maneiras variadas, distribuindo as funções diferentemente (ROSSO, 1980). Embora o termo enfatize a expansibilidade das residências, os termos habitação flexível ou habitação adaptável $^{1}$ são utilizados com o mesmo propósito.

As ideias relacionadas às habitações e edificações flexíveis em geral apresentam vários registros na literatura, com casos citados, desenvolvidos a partir do século dezenove ${ }^{2}$. Ao longo dos anos,

\footnotetext{
${ }^{1}$ Alguns autores diferenciam flexibilidade e adaptabilidade. Para Pedro (2000), a adaptabilidade é uma das duas qualidades do grupo denominado personalização. A outra é a apropriação. Para Russel e Moffatt (2001), o conceito de flexibilidade insere-se como uma estratégia da adaptabilidade, que é, por sua vez, o conceito mais amplo. Friedman (2002) também considera a adaptabilidade como sendo o conceito geral. Já Brandão (2002; 2003) traz a adaptabilidade apenas como uma dentre cinco categorias de concepção flexível. Em um trabalho mais recente, Till e Schneider (2005), também consideram a flexibilidade como sendo a categoria maior e mais geral. Para o presente artigo, no entanto, os termos flexibilidade e adaptabilidade foram considerados equivalentes.

${ }^{2}$ Cento e setenta e cinco casos expressivos, constam da pesquisa Flexible Housing Project, realizada na Escola de Arquitetura da Universidade de Sheffield, no período de 2004-06, conduzida pelos Professores Jeremy Till, Sarah Wigglesworth e Tatjana Schneider. Os casos catalogados são de 1850 até os dias atuais, oriundos de 19 países, a maioria europeus.

<http://www. afewthoughts.co.uk/flexiblehousing/>.
}

muitas propostas incluíram o uso da pré-fabricação industrializada, como o exemplo da Figura 1, sendo a flexibilidade concordante com os princípios chave da ideologia Modernista (SCHNEIDER; TILL, 2005).

Segundo Skidmore, Owings e Merril (1942), uma moradia consiste de um vocabulário (estrutura e elementos de instalações, vedações e mobiliário), uma gramática (relações funcionais do vocabulário) e composição (a expressão final no projeto). Neste exemplo, as plantas eram modificadas e expandidas progressivamente e as instalações poderiam ser substituídas quando consideradas obsoletas.

\section{A necessidade de modificar a moradia}

No âmbito do morar, a territorialidade é exercida pelos moradores pelo controle sobre o espaço. A colocação de objetos com significado especial ou de características específicas dentro e fora da casa, o arranjo dos móveis, assim como a manutenção da casa, são todos comportamentos territoriais. A casa exerce um papel crucial na definição da identidade pessoal e social das pessoas, agindo como um diálogo entre elas e a comunidade em geral. Além disso, como comenta Després (1991), mesmo que as pessoas não tenham a intenção de comunicar informações sobre sua posição social, esta pode ser decodificada por outros.

As razões pelas quais o usuário deseja promover alterações em sua habitação são várias, sendo forte a ligação com fatores simbólicos e estéticos (BRANDÃO, 2002; 2005). Estas alterações, explicadas por Reis (1995), estão relacionadas com: aspectos funcionais como disposição e tamanho das peças; tamanho da moradia; aspectos ligados à privacidade visual e auditiva; aspectos ligados a questões estéticas; aspectos ligados a questões de personalização e definição do território; alterações no tamanho da família, nível econômico e educacional, dentre outros.

Avaliações pós-ocupação em conjuntos
habitacionais mostram, normalmente, a
insatisfação com o tamanho da casa e com a
adequação dos cômodos. As modificações
observadas não seguem uma regra geral,
dependem da maior ou menor adequação do
projeto original, porém, ampliações de cozinhas e
criação de novas dependências, como edículas, são
frequentes (REIS, 1995; 2000; BITTENCOURT;
SILVA, 1996; SZÜCS, 1998). O morador expressa
o desejo de fornecer à sua residência, dentro do
que é possível, uma característica individual tanto
dentro como fora (Figura 2).

Avaliações pós-ocupação em conjuntos habitacionais mostram, normalmente, a insatisfação com o tamanho da casa e com a adequação dos cômodos. As modificações observadas não seguem uma regra geral, dependem da maior ou menor adequação do projeto original, porém, ampliações de cozinhas e criação de novas dependências, como edículas, são frequentes (REIS, 1995; 2000; BITTENCOURT; SILVA, 1996; SZÜCS, 1998). O morador expressa o desejo de fornecer à sua residência, dentro do dentro como fora (Figura 2). 


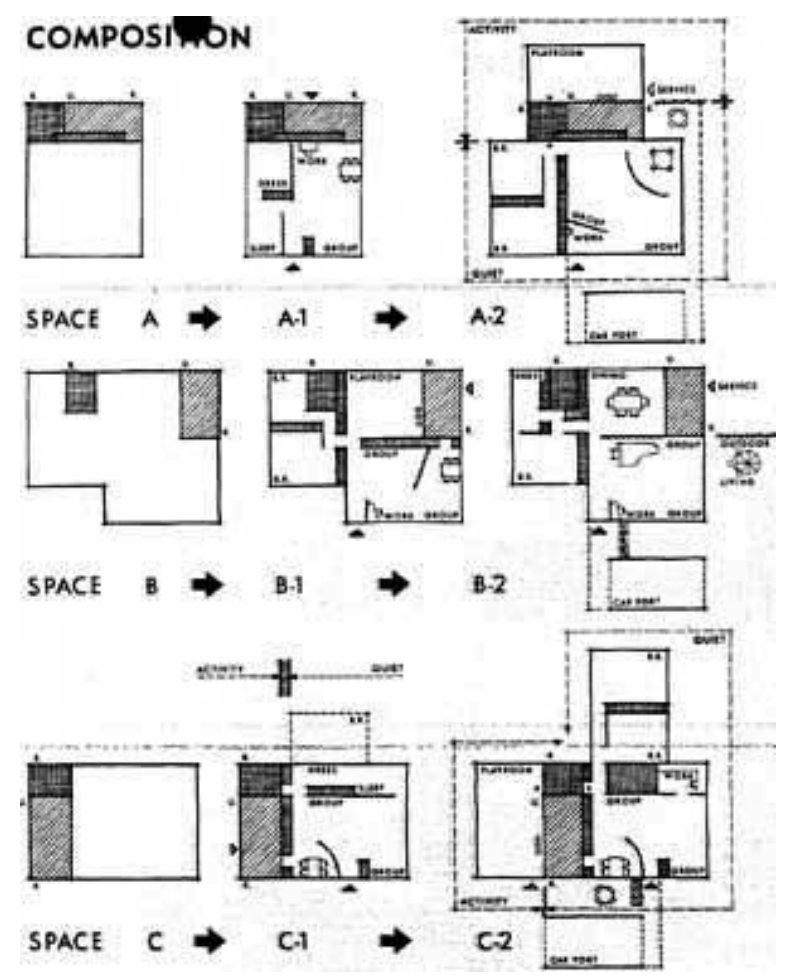

Figura 1 - Flexible Space, E.U.A., 1942: proposta dos arquitetos Skidmore, Owings e Merril (SOM) Fonte: Skidmore, Owings e Merril (1942).

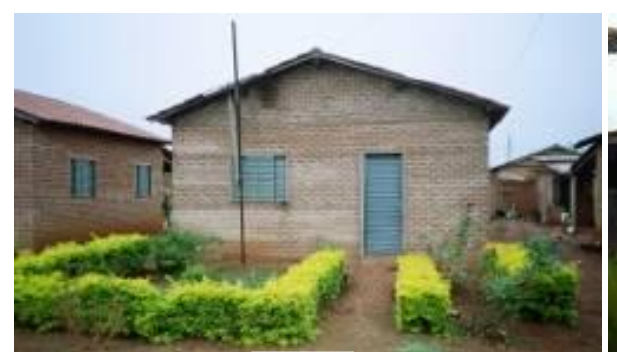

(a)

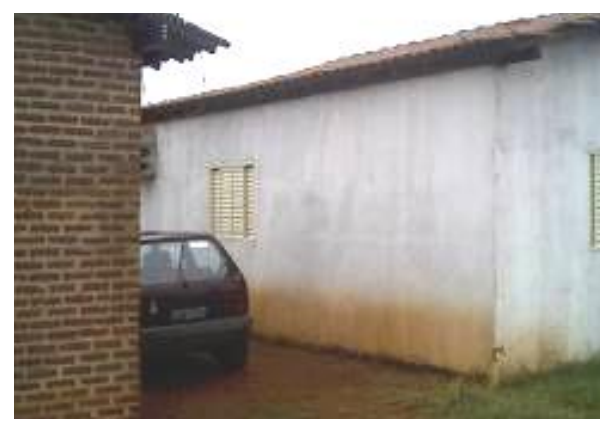

(c)

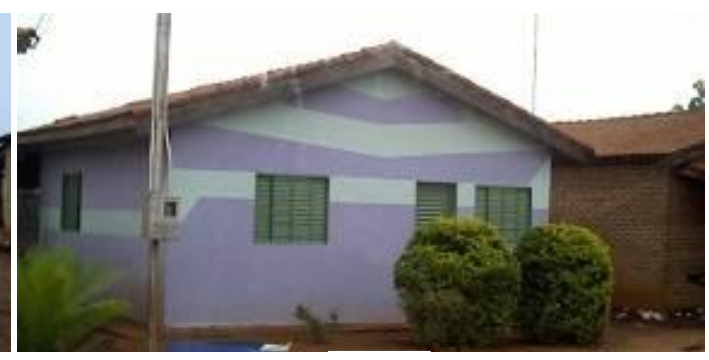

(b)

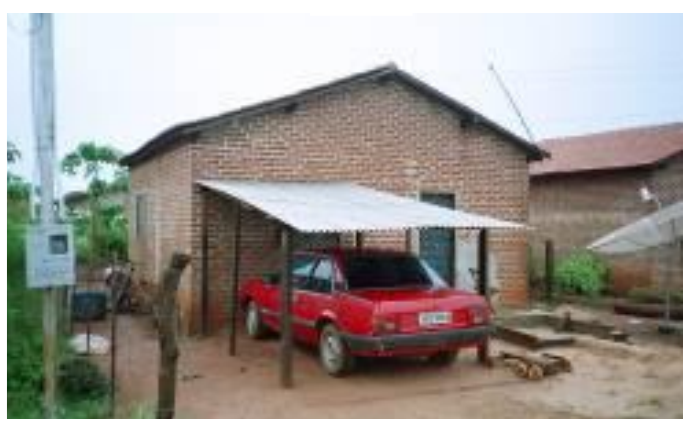

(d)

Figura 2 - Personalização de casas no Município de Itiquira, Mato Grosso: (a) por meio de um jardim; (b) por meio de pintura; e (c) e (d) automóvel, como parte da propriedade 


\section{Importância das habitações flexíveis}

A flexibilidade, de acordo com Galfertti (1997), é um dos objetivos da modernidade. É um mecanismo efetivo para compensar a lacuna na conexão entre o arquiteto e o ocupante desconhecido. $\mathrm{Na}$ definição deste autor, flexibilidade é o grau de liberdade que torna possível a diversidade de modos de vida. Vários autores defendem a importância da flexibilidade, tanto na ocupação inicial dos espaços (flexibilidade inicial), como ao longo de sua utilização (flexibilidade contínua, funcional ou permanente). A organização do espaço e o projeto devem ser compatíveis com diferentes padrões de vida no decorrer do tempo, ou seja, com multiplicidade de usos. O conceito de habitação evolutiva exige previsão e projeção no projeto.

No entanto, a dificuldade em gerar usos duradouros se deve, principalmente, à forma tradicional de projetar, baseada na perspectiva funcionalista clássica, caracterizada pela especificação extrema ${ }^{3}$ de requisitos. A falta de flexibilidade de projeto, de acordo com Paduart et al. (2009), é uma das causas de intervenções, demolição parcial e, até mesmo, a demolição completa de uma edificação. A rápida obsolescência de soluções demasiadamente específicas conduz a uma grave falta de eficiência, segundo Hertzberger (1999), que defende a polivalência.

Friedman (1997) defende que a casa deve ser projetada para ser adaptável ao mercado de usuários desconhecidos:

(a) no estágio de pré-ocupação o construtor deve modificar a moradia às necessidades de diferentes tipos de famílias; e

\footnotetext{
${ }^{3}$ Esta tendência é recorrente no Brasil e em vários países. A excessiva determinação nos projetos é criticada por muitos autores. Callado (1995), por exemplo, apresenta os resultados da comparação de dois edifícios residenciais em Portugal, demonstrando que nos apartamentos com cômodos neutros a satisfação dos moradores era, em média, maior que nos apartamentos com espaços determinados e hierarquizados. Outros autores, como Schneider e Till (2005), discutem a oferta do setor privado de habitações na Inglaterra: "o número de cômodos é visto como mais importante que o tamanho destes, a tendência do setor privado de habitações é a redução dos espaços aos padrões mínimos e a tipificação dos cômodos". Ou seja, a habitação oferecida naquele país (e também no Brasil) apresenta cômodos que só podem ser usados de um modo único, pré-determinado, devido ao tamanho e forma dos mesmos. Para Schneider e Till é visível o desinteresse dos empreendedores do mercado imobiliário inglês em prover habitações adaptáveis. Pelo contrário, passa-se a visão de que a moradia é somente mais um item de consumo: uma vez que não atenda mais a família, basta adquirir outra. E, mesmo a habitação de promoção pública, apesar de defender a adequação da moradia ao longo do tempo, define um número muito grande de regras e exigências, o que também acaba dificultando o potencial de utilização da flexibilidade nos projetos.
}

(b) no estágio de pós-ocupação a casa também deve responder às necessidades de mudança espacial, além de ser facilmente adaptável às necessidades dos primeiros e dos subsequentes proprietários.

A demanda por habitações mais flexíveis se faz perceber com base em fatores sócio-demográficos, com uma maior diversificação demográfica e dos modos de vida, pelo surgimento de novas composições familiares, não tradicionais (BRANDÃO, 2002; 2003). Digiacomo (2004) acrescenta, como fatores, a diversidade cultural, a redução das áreas úteis das habitações e, a própria necessidade de inovar.

No entanto, os empreendimentos habitacionais, independente da forma de promoção, pública ou privada, são oferecidos quase sempre, com plantas recorrentes por anos e anos. Mesmo em habitações de pequena área, o que se observa são plantas com excessiva compartimentação e tripartição de setores. Villà (2007) comenta que

\section{[...] o mercado continua vendendo a localização do empreendimento habitacional, a área construída e o velho programa $1 D, 2 D$, 3D e 4D. Além de status, segurança e etc. [...]}

Para Villà, a sociedade tem que enfrentar a difícil questão de adequar sua moradia à realidade que vive e que não é contemplada pela oferta imobiliária.

Mas, a despeito da carência de novos desenhos e novas possibilidades, a importância de promover diversidade e flexibilidade tem sido enfatizada no Brasil em vários estudos recentes realizados sobre o mercado da construção civil brasileira. Alguns exemplos são: Brandão (1997 e 2002), Campanholo (1999), Círico (2001), Moschen (2003), Digiacomo (2004), Carvalho (2004), Payeras (2005), Marroquim e Barbirato (2007), Tillmann (2008) e Finkelstein (2009).

Palermo et al. (2007) comentam que nenhuma nação tem a capacidade de criar o projeto ideal, aquele que atenderia a totalidade de necessidades presentes e futuras da família moradora. E o Brasil, em particular, com sua diversidade cultural, apresenta características ainda mais complexas quando em um mesmo grupo social, são percebidas diferentes formas de utilização dos ambientes da casa. Estes autores defendem duas estratégias de projeto: a flexibilidade de execução, permitindo a construção em etapas, e a flexibilidade de uso, que facilite a adequação dos espaços às necessidades físicas específicas da família moradora, incluindo eventuais necessidades especiais, com garantia da 
acessibilidade espacial a pessoas com diferentes níveis de restrição.

Sobre este último aspecto, vale ressaltar que acessibilidade e adaptabilidade não são categorias absolutas de projeto, como comenta Alonso (2002). São, sim, dois conceitos que se complementam na provisão de elementos e requisitos para atender os variados tipos de usuários do ambiente construído.

Atualmente, os estudos acerca da flexibilidade habitacional buscam novas abordagens, menos prescritivas, métodos que possibilitem avaliar e identificar propostas arquitetônicas robustas e verdadeiramente efetivas neste quesito. Estudos como os de Till e Schneider (2005) têm ido nesta direção. Mais do que definir graus de versatilidade física, alternativas de arranjos e mobilidade (tanto na ocupação inicial da residência como durante o seu uso), importa mais explorar a questão de determinação ou indeterminação do projeto, associada à categorização dos modos de uso e dos níveis de tecnologia (soft ou hard). A defesa destes autores é por projetos "incompletos", balanceados em seus níveis de indeterminação, e associados à tecnologias "soft". Isto corrobora conceitos de autores anteriores, como Galfertti (1997), que afirmava que uma flexibilidade leve, associada a tecnologias low-tech, formava o binômio mais plausível para a construção do futuro.

\section{Método de pesquisa}

Este estudo se utiliza de parte dos resultados do Projeto Moradia, Programa Habitare, desenvolvido de 2003 a 2006, por grupos de pesquisa do, então, Centro Federal de Educação Tecnológica de Mato Grosso $\left(\right.$ CEFETMT) ${ }^{4}$ e da Universidade Federal de Mato Grosso (UFMT). Neste período, foram realizadas visitas para avaliar a forma de ocupação e satisfação dos moradores de dois conjuntos residenciais construídos em sistema de mutirão: 15 casas do Residencial Arco Íris II, no município de Itiquira, e 24 casas em Ouro Branco do Sul, distrito do próprio município de Itiquira, na região sul do Estado de Mato Grosso (DADAM; BRANDÃO, 2005). Para cada casa, obteve-se a disposição do mobiliário e o desenho das ampliações, além da resposta dos moradores à questões sobre a satisfação com a moradia, sobre as razões das ampliações realizadas e sobre aquelas que estavam nos planos futuros da família.

$\mathrm{Na}$ primeira etapa foram levantadas e analisadas as características das modificações espontâneas realizadas pelos moradores, relacionando os

\footnotetext{
${ }^{4}$ Atualmente, Instituto de Educação, Ciência e Tecnologia de
} Mato Grosso (IFMT). problemas comuns decorrentes de projetos que não contemplam a flexibilidade. Um dos resultados desta primeira avaliação foi a publicação de um pequeno manual técnico, contendo uma série de soluções para o projeto da habitação social evolutiva (BRANDÃO, 2006). Posteriormente, de 2007 a 2009, foram realizadas avaliações pósocupação em quatro protótipos do Projeto Moradia, construídos em Barra do Bugres, cidade situada cerca de $150 \mathrm{~km}$ a noroeste de Cuiabá, ampliando o acervo de informações sobre a disposição do mobiliário e o modo de morar das famílias.

Para não se limitar a uma simples proposição de soluções técnicas, o retorno à literatura especializada na área de Planejamento e Projeto das Edificações foi necessário, como forma de obter diretrizes robustas, mais amplas e organizadas. Os trabalhos de Paiva (2002) e Digiacomo (2004) foram os que apresentaram uma melhor estruturação para os grupos das estratégias de flexibilidade, sendo definidas onze categorias ${ }^{5}$ :

(a) concepções de equipamentos, instalações e mobiliário;

(b) alteração da compartimentação;

(c) forma de circulação;

(d) espaços neutros e polivalência de usos;

(e) concepção estrutural;

(f) concepção das fachadas;

(g) localização e número de acessos;

(h) alteração da área útil e dos limites da construção;

(i) desenho da arquitetura ${ }^{6}$;

(j) estratégias de padronização de componentes; e (k) manual de instruções.

Para a análise pretendida também foram considerados nove princípios gerais, conforme mostra o Quadro 1.

As disposições técnicas ou diretrizes são, praticamente, estratégias mais específicas e detalhadas dentro dos grupos de estratégias. Já os princípios são as linhas gerais, nas quais todas as diretrizes e estratégias estão inseridas.

\footnotetext{
${ }^{5}$ Os grupos de $a$ até $h$ são propostos por Paiva (2002) e de $i$ até $k$, propostos por Digiacomo (2004).

${ }^{6}$ Inclui as seguintes estratégias: planta livre, preparação da casa para as possibilidades de expansão vertical, lateral e para os fundos, união de unidades, ambientes reversíveis, ambientes multiuso, alternância entre isolar e integrar e baixa hierarquia (ambientes com pouca variabilidade de tamanho entre si).
} 


\begin{tabular}{|c|c|}
\hline 1. Independência & $\begin{array}{l}\text { Características que permitem remoção e acréscimo sem afetar a eficiência dos } \\
\text { sistemas interconectados. }\end{array}$ \\
\hline 2. Upgradability & $\begin{array}{l}\text { Sistemas e componentes que permitem acréscimos, expansões e atualizações para } \\
\text { melhoria da eficiência dos sistemas. }\end{array}$ \\
\hline $\begin{array}{l}\text { 3. Compatibilidade de } \\
\text { ciclos de vida }\end{array}$ & $\begin{array}{l}\text { Previsão de sistemas e componentes com tempos de duração similares, sobretudo } \\
\text { naqueles que são interconectados. }\end{array}$ \\
\hline 4. Informação & $\begin{array}{l}\text { Registros de desenhos, especificações e limitações dos projetos, de modo a auxiliar } \\
\text { em futuras análises de custos de adaptações e expansões. }\end{array}$ \\
\hline 5. Durabilidade & $\begin{array}{l}\text { Duração de materiais, elementos e componentes, com relação a reparos, manutenção } \\
\text { e substituição. Espaços duradouros também estão incluídos. }\end{array}$ \\
\hline 6. Versatilidade & Forma ou arranjo do espaço que permite alternativas de uso. \\
\hline $\begin{array}{l}\text { 7. Facilidade de acesso às } \\
\text { instalações }\end{array}$ & $\begin{array}{l}\text { Forros rebaixados, pisos elevados, shafts e outras soluções que permitem acesso fácil } \\
\text { a tubulações, dutos, fiações e equipamentos. }\end{array}$ \\
\hline 8. Redundância & $\begin{array}{l}\text { Estruturas projetadas para receber cargas maiores, instalações dimensionadas para } \\
\text { expansão, elementos adicionais (superprovisão). }\end{array}$ \\
\hline 9. Simplicidade & $\begin{array}{l}\text { Ausência de complexidade dos sistemas, projetos racionalizados, estruturas e } \\
\text { componentes modulares, materiais convencionais, etc. }\end{array}$ \\
\hline
\end{tabular}

Quadro 1 - Princípios que contribuem para a adaptabilidade das edificações, durante a fase de uso Fonte: CMHC e CANMET (1997) ${ }^{7}$ apud Russel e Moffatt (2001, p. 7-9).

O estudo foi orientado pelas seguintes questões:

(a) que tipos de dificuldade costumam ocorrer quando o usuário deseja promover modificações em sua moradia? (sobretudo nos casos de ampliação);

(b) que orientações (diretrizes) podem ser adotadas para a obtenção de projetos mais flexíveis? E como estas podem ser organizadas?; e

(c) as diretrizes propostas são suficientes para gerar projetos evolutivos, ou se faz necessário pensar em novas alternativas, novos desenhos para o espaço doméstico?

\section{Modificações mais frequentes em HIS}

Digiacomo (2004) levantou as modificações mais frequentes em habitações sociais observadas em cidades do Estado de Santa Catarina. Foram:

(a) intervenções na fachada, incluindo construção de um muro e/ou gradil;

(b) ampliação na cozinha para criar área de refeições e acomodar inúmeros eletrodomésticos;

(c) criação ou aumento a área de serviço; (d) separação de local para negócios, estudos e hobbies:

(e) acréscimo de banheiros ou lavatórios;

(f) provisão de armários adicionais para roupas, livros e equipamentos;

(g) alteração de relacionamentos entre cozinha, jantar e salas de estar, por fechamento ou abertura; e

(h) criação de sala de televisão (vide Figura 4).

Nas cidades do interior de Mato Grosso, por sua vez, outros tipos de modificação foram levantados, como apresentado adiante.

\section{Ampliações}

Num primeiro momento, as ampliações caracterizam a maioria dos tipos de modificação que são feitas nas casas populares, sobretudo pela pequena área do projeto original. A Figura 3 mostra casos de ampliação lateral que afetam a fachada. A Figura 4 mostra ampliações para frente e a Figura 5, ampliações para os fundos. A Figura 6 já mostra o caso de ampliação que visa o uso parcial da casa para comércio.

\footnotetext{
${ }^{7}$ CANADA Mortgage Housing Corporation; CANADA'S Clean and Renewable Energy Research Centre. Building Adaptability: a survey of systems and components, Ottawa, maiy 1997.
} 


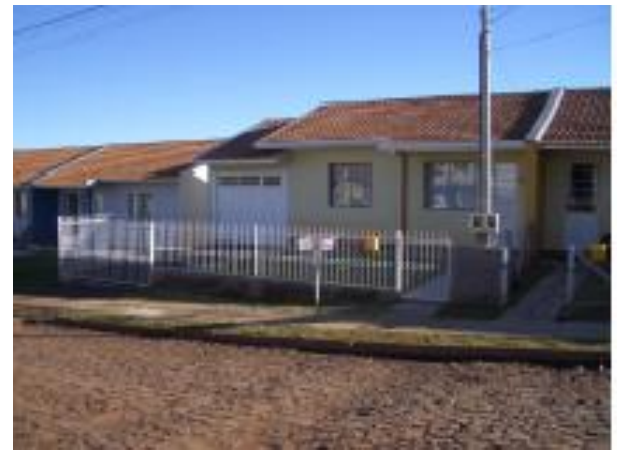

(a)

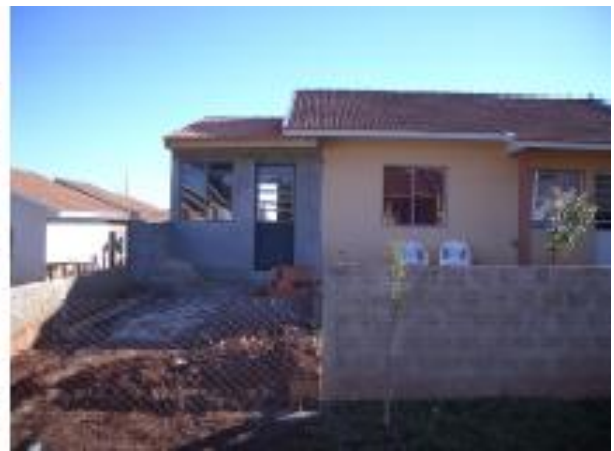

(b)

Figura 3 - Empreendimento Nova Aurora, na cidade de Chapecó: (a) criação de garagem e gradil; e (b) construção de unidade para aluguel e muro

Fonte: Digiacomo (2004).

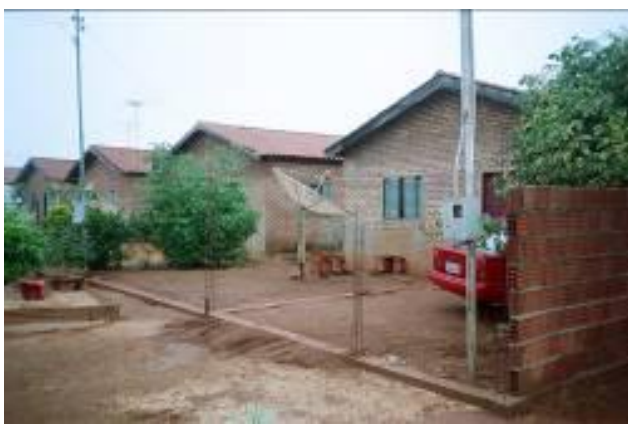

(a)

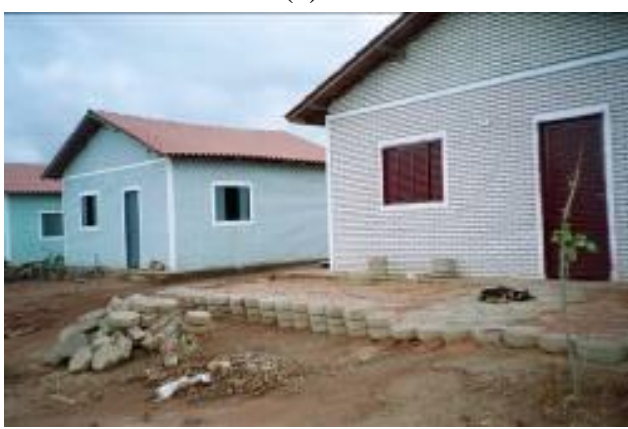

(c)

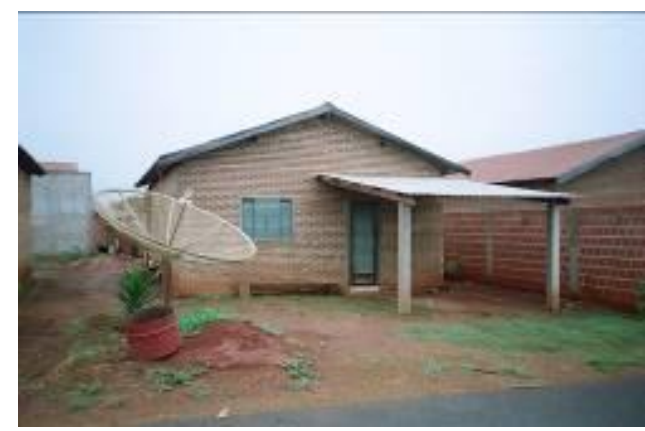

(b)

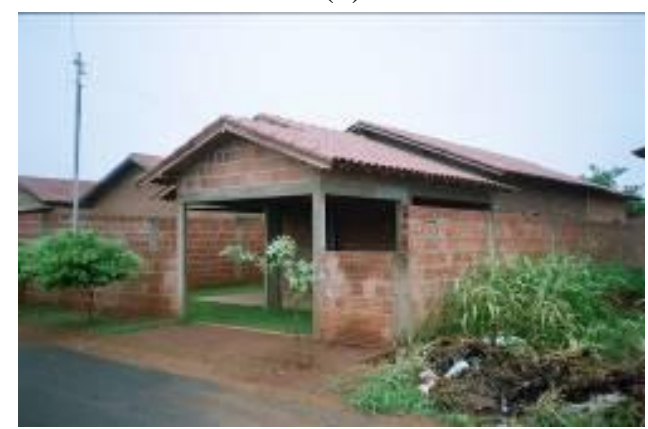

(d)

Figura 4 - Ampliações na frente: (a) construção de base para ampliação; (b) criação de varanda; (c) construção de pavimento; e (d) criação de garagem, varanda e muro

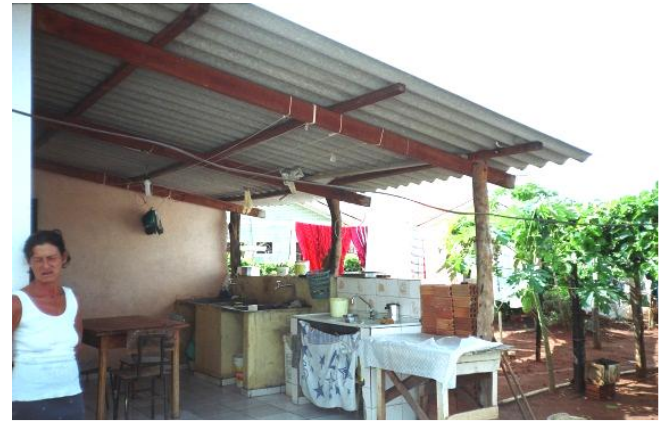

(a)

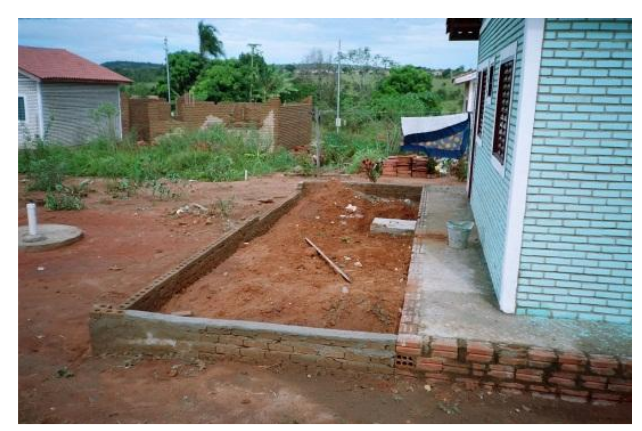

(b)

Figura 5 - Ampliações aos fundos: (a) construção de área multiuso, com tanque de lavar, pia de cozinha e mesa para refeições; e (b) preparação de alicerce 


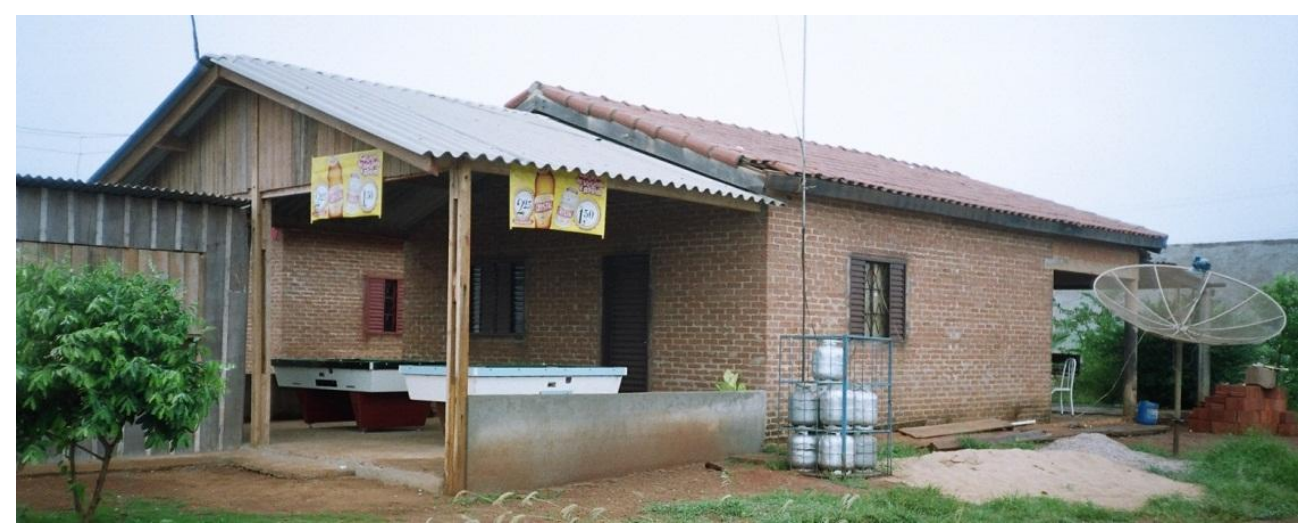

Figura 6 - Parte da casa foi destinada a funcionar como bar ou mercearia - também foi ampliada aos fundos

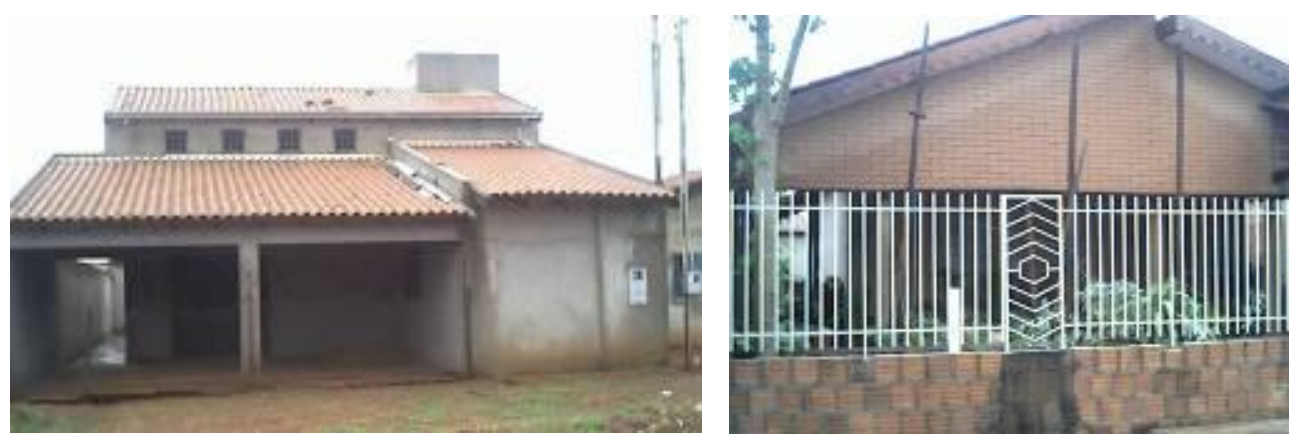

Figura 7 - Casas construídas, originalmente, com tijolos de solo-cimento, com área inicial em torno de $42 \mathrm{~m}^{2}$ - a casa à esquerda foi totalmente descaracterizada em relação ao projeto original

É também normal observar os casos em que a residência é totalmente descaracterizada. Isso remete à reflexões acerca do cunho social de alguns projetos nos quais a descaracterização das casas se dá precocemente. Reforça o aspecto da valorização da terra em detrimento às benfeitorias ali produzidas, beneficiando muitas vezes aqueles que, muito provavelmente, não necessitam de auxílio social. A Figura 7 mostra dois exemplos de casas muito modificadas.

\section{A dificuldade de ampliação das moradias típicas}

Tomando a Figura 8, dois casos de ampliação espontânea são apresentados. Na primeira casa, o morador cria dois quartos em terreno lateral, além da ampliação feita nos fundos. Nota-se que a solução só se viabiliza, utilizando um dos quartos originais como circulação de acesso aos novos cômodos. Na segunda residência, um dormitório extra foi criado aos fundos, além de varandas na frente e nos fundos. É visível que a forma da planta, associada ao formato do telhado, prejudicou neste caso as possibilidades de ampliação.
É na cobertura que as ampliações espontâneas realizadas em projetos engessados mostram um dos piores resultados: a falta de harmonia estéticoarquitetônica dos telhados, com mescla de materiais diferentes (Figura 8). Além disso, o banheiro é projetado, frequentemente, em parte central e aos fundos da casa, como mostra a mesma figura, uma configuração que reduz as possibilidades de ampliação adequada da casa para os fundos.

Na Figura 8b observa-se que a janela original do quarto ao lado do banheiro foi transferida para a parede lateral, permitindo a criação do dormitório adicional aos fundos. As esquadrias, quando mal posicionadas inicialmente, dificultam as ampliações, gerando mais trabalho e custos que poderiam ser evitados.

Com a limitação de área, as cozinhas são normalmente pequenas, não permitindo espaço para adequado para refeições. Esta função acaba sendo acumulada pela sala de estar que também, normalmente, não comporta a mesa com cadeiras. Observa-se que muitas das ampliações aos fundos são feitas para funcionar como nova cozinha (às vezes como uma segunda cozinha), obtendo-se maior espaço para refeições. Outra constatação é 
que grande parte das famílias de conjuntos mais carentes não possui mobiliário com dimensões adequadas para uma residência pequena. Em geral, estes móveis são maiores devido à forma com que foram originados: trazidos de residências anteriores, recebidos por meio de doação ou adquiridos no comércio de móveis usados. É comum verificar a existência de fogões maiores, de seis bocas, por exemplo, que não cabem nos espaços que originalmente haviam sido planejados para fogões pequenos. ${ }^{7}$
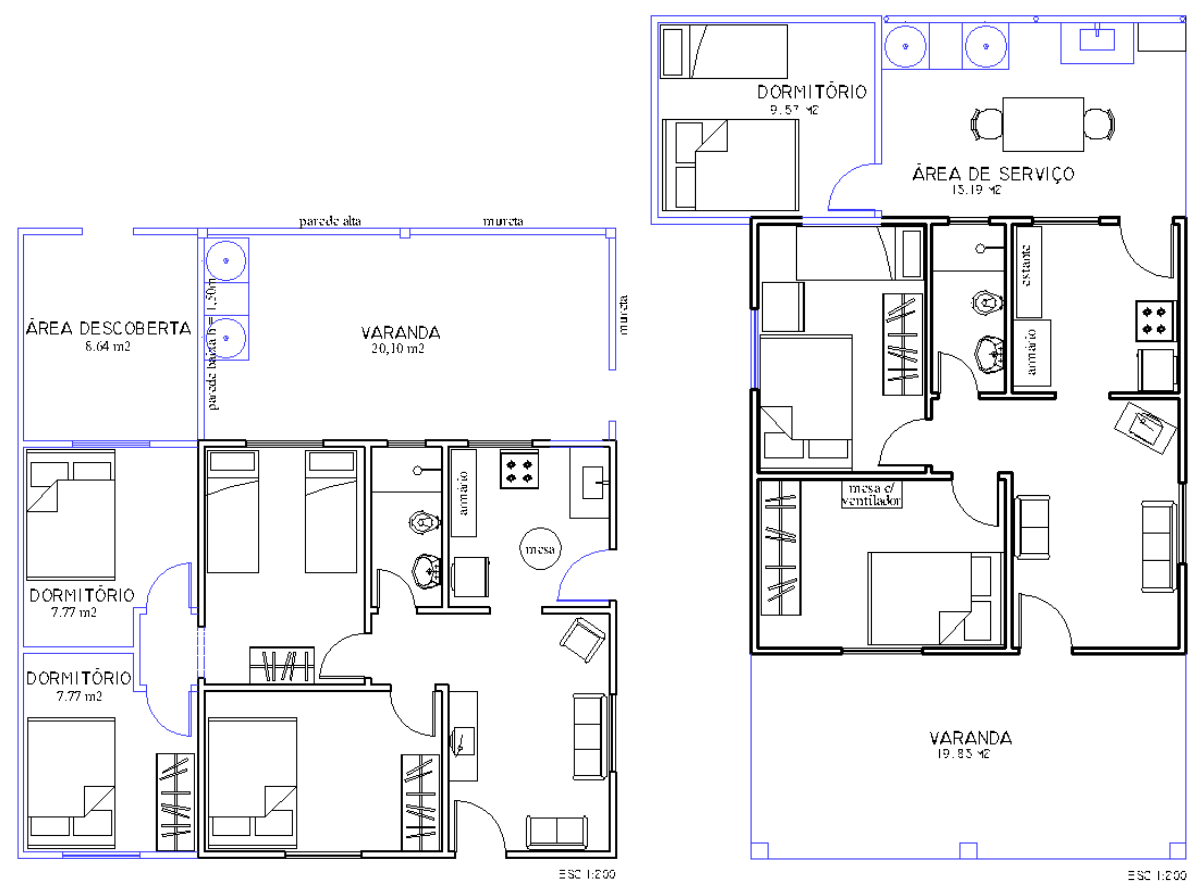

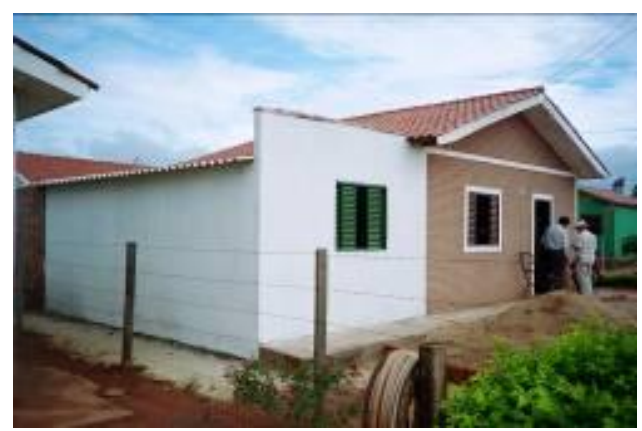

(a)

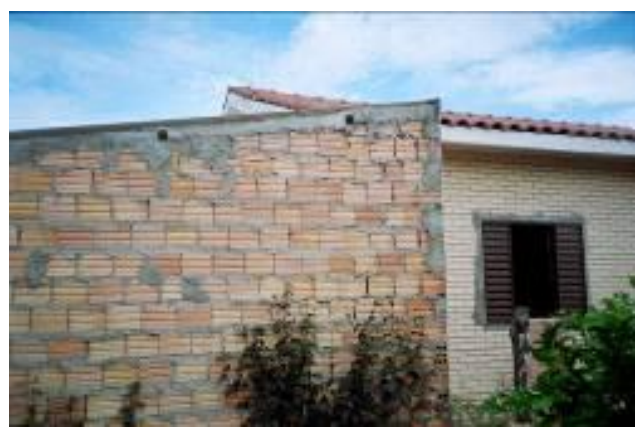

(b)

Figura 8 - Conjunto Habitacional Arco Íris II, Itiquira, Mato Grosso: exemplos de ampliações realizadas de forma precária

Fonte: Dadam e Brandão (2005).

Fotos: do autor.

\footnotetext{
${ }^{8}$ Trata-se de uma situação que, aos poucos, tem-se alterado no Brasil, com a melhoria gradual do poder aquisitivo da população mais carente, sobretudo a partir da segunda metade dos anos 2000 , havendo mais acesso à aquisição de móveis e eletrodomésticos novos.
} 
Na maioria dos projetos o tanque é externo (Figura 9) e a responsabilidade pela cobertura da área de serviço é do usuário, após a ocupação. Inclusive, vale comentar que nem sempre a posição da casa no terreno privilegia melhores ampliações.

\section{Disposições técnicas e diretrizes de projeto}

A seguir são apresentadas 31 diretrizes que foram organizadas com relação ao arranjo espacial, esquadrias e aberturas, cobertura, estrutura, instalações, divisão de ambientes, mobiliário, posição da casa no terreno, tipologias e, por fim, apoio ao usuário. Estas disposições técnicas e diretrizes para projetos de moradias populares unifamiliares foram levantadas a partir de pesquisa bibliográfica e das observações feitas com as visitas às residências nos municípios de Itiquira e Barra do Bugres, em Mato Grosso.

\section{Arranjo espacial quanto à forma e dimensão dos cômodos}

Prover cômodos neutros e sem extremos de tamanho. Criar ambientes similares, praticamente equivalentes, em forma e tamanho, sem uma função pré-determinada. A Figura 10 mostra um exemplo de adoção da neutralidade no projeto.

Prover cômodos ou ambientes multiuso. A agregação ou sobreposição de funções pode ser determinada no projeto. Na moradia social, criar um ambiente integrado, unindo cozinha e estar, é uma estratégia recomendada. Para Palermo (2009) isto permite melhorar as soluções para o espaço de refeições.

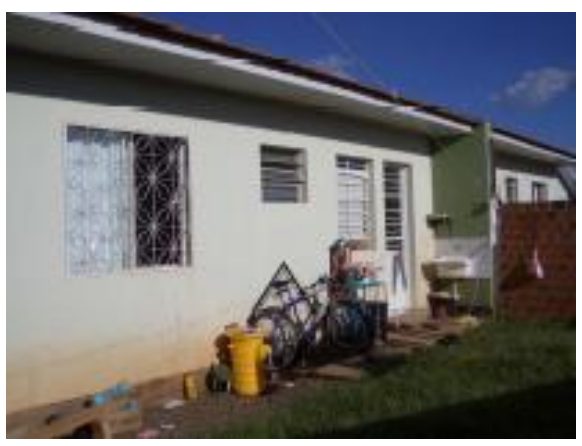

Figura 9 - Empreendimento Nova Aurora, em Chapecó, Santa Catarina: tanque de lavar localizado em área descoberta, situação corriqueira nos projetos voltados para famílias de baixa renda no Brasil Fonte: Digiacomo (2004).

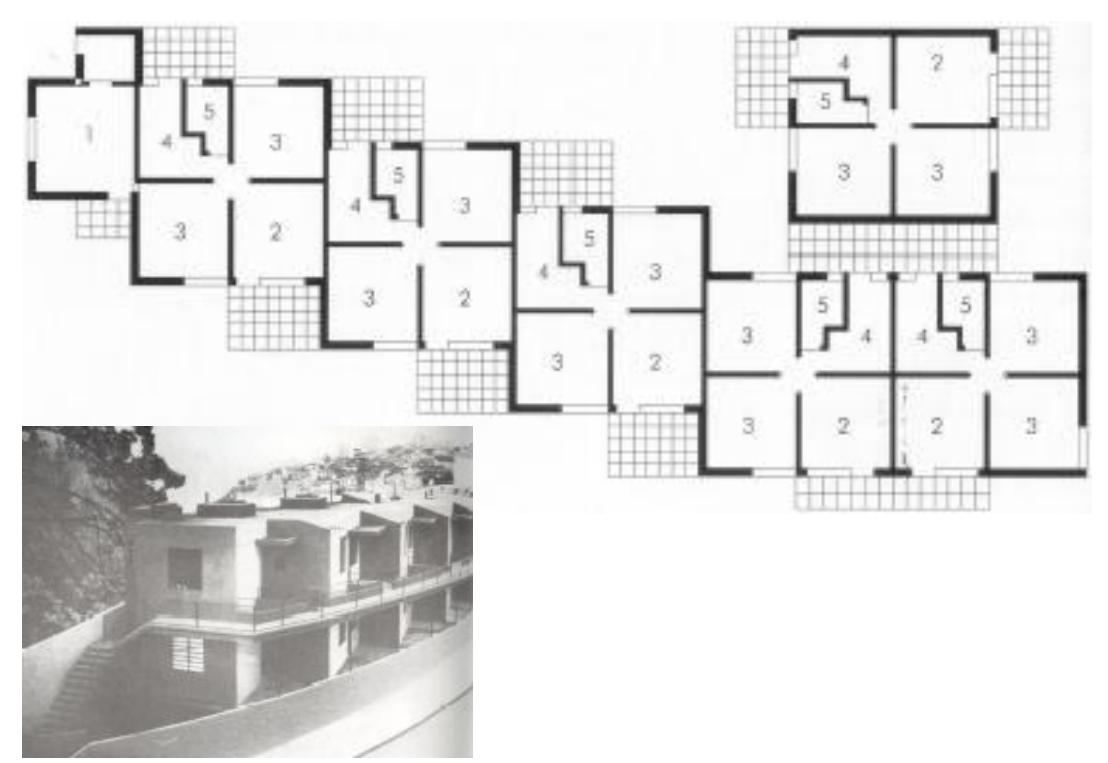

Figura 10 - Vila Operária, Rio de Janeiro, anos 40 Fonte: Cavalcanti (2001). 
Prever a possibilidade de nova posição de porta no banheiro. Com uma segunda porta é possível criar um banheiro de suíte (fechando ou mantendo a primeira abertura). A adoção de duas portas para um mesmo cômodo, apesar de configurar superprovisão, permite a multifuncionalidade do respectivo espaço.

Prever, se possível, espaço de refeições maior nas cozinhas. Apesar de ser uma diretriz difícil de ser alcançada, dada a exiguidade dos espaços, a mesma deve ser perseguida pelos projetistas. Uma copa-cozinha, mais ampla, não serve apenas para estocar, preparar, cozinhar os alimentos e realizar as refeições. Uma cozinha mais ampla é um espaço de vivência, onde muitas outras funções são realizadas (ALBERS; HENZ; JACOB, 1989).

Estudar a opção de usar ou não corredores dentro da unidade. Uma pequena circulação normalmente é prevista para a conexão dos quartos e do banheiro, aumentando um pouco a privacidade destes cômodos. Um pequeno corredor pode ser usado como forma de induzir as ampliações. Uma circulação um pouco maior permite outras funções, como estocagem, ou espaço para computador, por exemplo. Por outro lado, a não utilização de circulações traz economia, permitindo criar ou ampliar outros ambientes.

\section{Arranjo espacial quanto ao sentido de expansão da moradia}

Deixar claro o sentido de expansão da moradia. Digiacomo (2004) alerta quanto a evitar o conhecido "puxadinho", que pode deixar os fluxos de circulação complicados e atrapalhar a luz e o ar natural na parte original da casa. $\mathrm{O}$ projeto deve induzir a expansão apenas para os lados que não afetem negativamente, nem a edificação original, nem as de seus vizinhos.

Digiacomo (2004) defende que, para se determinar o sentido da ampliação, deve-se limitar o número de fachadas livres para serem ampliadas. Há, no entanto, projetos de casa-embrião concebidos para receber ampliações em todas as direções, como é o caso, por exemplo, da proposta apresentada à Figura 11.

O mais importante é que estes sentidos de expansão da moradia sejam bem visíveis ao usuário. Normalmente o sentido das ampliações é para os fundos, para as laterais e para cima. A "Casa 1.0" proposta pela Associação Brasileira de Cimento Portland (Figura 12) constitui um exemplo de expansão para os fundos.

O Sistema Stella (Figura 13), protótipo construído no campus da Universidade Federal de Santa Catarina, utilizando madeira de reflorestamento, já caracteriza uma planta com fachada mais estreita e com maior profundidade. Neste caso a expansão lateral é a opção natural. Outro projeto que vale a pena destacar é o conjunto popular com casas geminadas duas a duas na cidade de Cotia, São Paulo (Figura 14). A possibilidade de expansão da casa neste caso já se dá na parte superior, onde há um espaço livre de reserva já coberto.

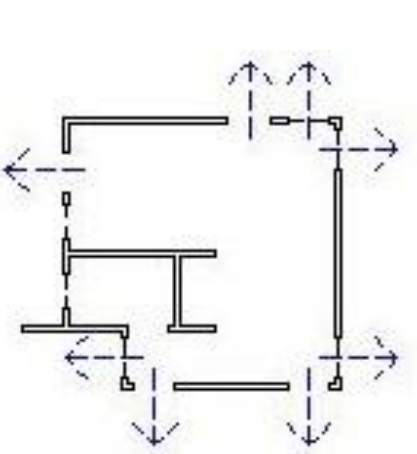

(a)

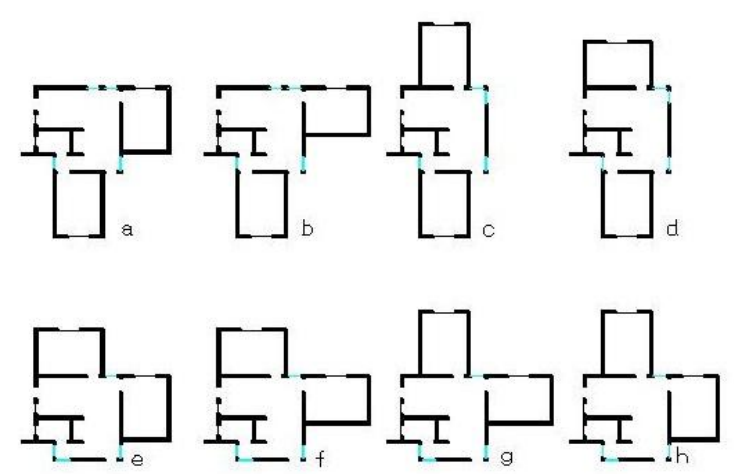

(b)

Figura 11 - "Projeto XIV", uma das propostas iniciais estudadas para o Projeto Moradia, Programa Habitare, em Mato Grosso: (a) o arranjo do embrião composto por sala, cozinha, banheiro e serviço, com as indicações dos vários sentidos de expansão; e (b) oito alternativas para acréscimo dos dois primeiros dormitórios da casa

Fonte: Rodrigues e Brandão (2005). 


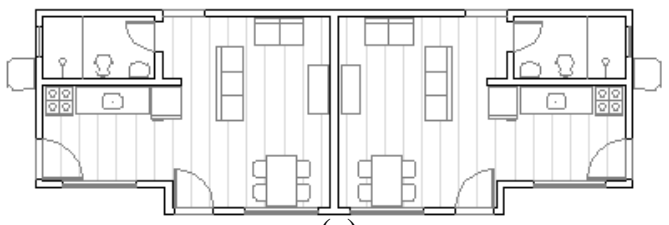

(a)

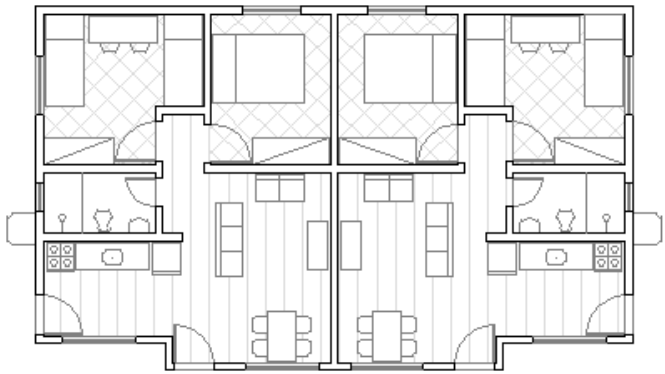

(b)

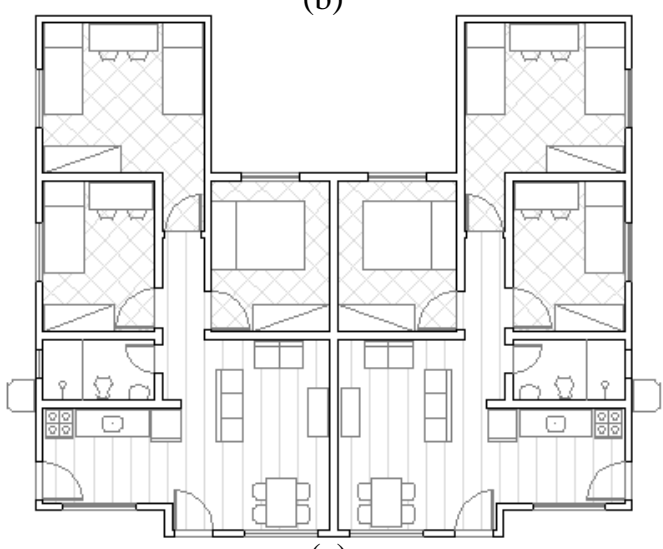

(c)
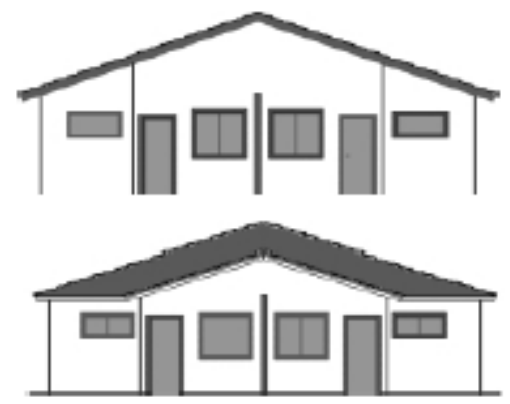

Figura 12 - “Casa 1.0", versão geminada, uma das propostas da Associação Brasileira de Cimento Portland (ABCP), para construção em alvenaria estrutural com blocos de concreto: (a) planta-embrião; (b) primeira etapa de ampliação, acrescentando dois dormitórios; e (c) segunda etapa de ampliação, acrescentando o terceiro dormitório Fonte: Associação Brasileira de Cimento Portland (2002).

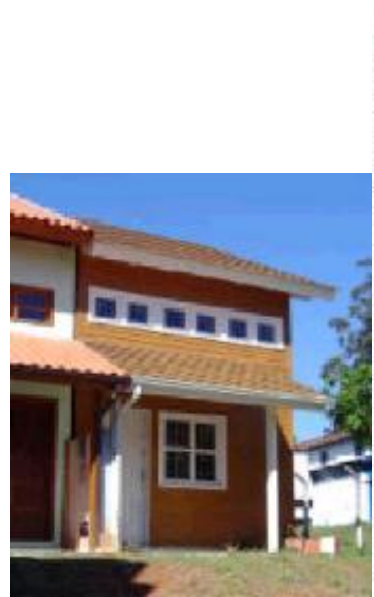

(a)

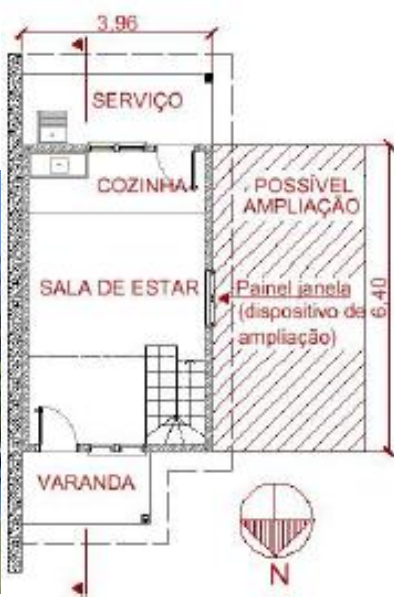

(b)

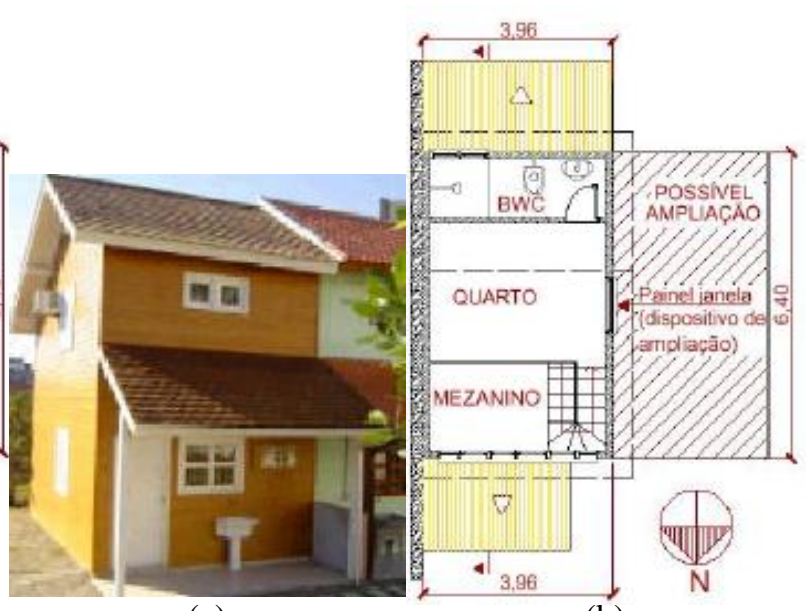

(a)

(b)

Figura 13 - Sistema Stella, protótipo construído no campus da Universidade Federal de Santa Catarina, com área de $47 \mathrm{~m}^{2}$, utilizando madeira de reflorestamento: (a) acima, vistas que mostram a opção de casas geminadas; e (b) as plantas destacam a possibilidade de ampliação no sentido lateral Fonte: Szücs et al. (2004). 
Vale comentar também a experiência chilena adotada a partir de 2001. Trata-se do trabalho da Elemental S.A., empresa associada à Companhia de Petróleo do Chile - COPEC e à Pontifica Universidade Católica do Chile, no campo da habitação de interesse social. Com o intuito de direcionar as futuras intervenções dos moradores nos conjuntos residenciais, a empresa desenvolve projetos delimitando as áreas para as ampliações. Esta solução arquitetônica evita o comprometimento estético do conjunto.
Aravena et al. (2004) descreve o projeto de Quinta Monroy implantado na cidade de Iquique, no Chile, onde uma das condicionantes projetuais foi estabelecer a direção do crescimento das habitações. A casa do primeiro piso podia ser ampliada sobre o solo, nas laterais e nos fundos. Já os apartamentos a partir do segundo piso tinham a possibilidade de construção nas laterais, verticalmente (Figuras 15 e 16).

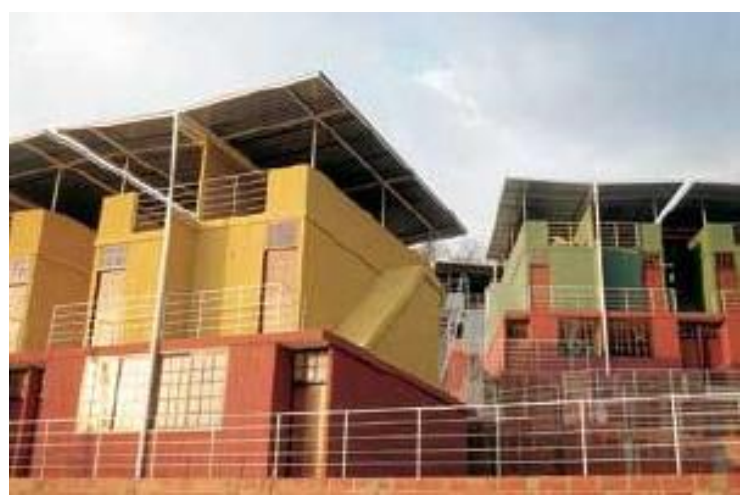

Figura 14 - Conjunto popular com casas geminadas duas a duas na cidade de Cotia, São Paulo, projeto de Joan Villà e Silvia Chile: (a) o térreo compreende sala, cozinha e área de serviço; (b) no primeiro pavimento há dois quartos e o banheiro; e (c) uma escada externa liga o primeiro pavimento ao terraço superior coberto, que funciona como área de expansão

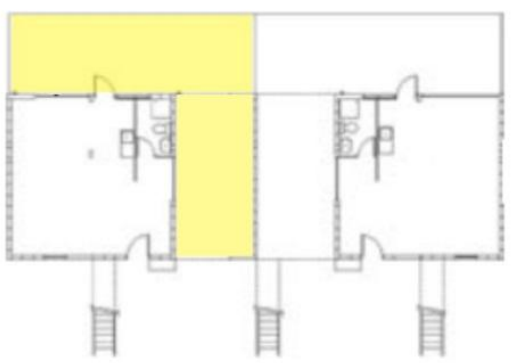

(a)

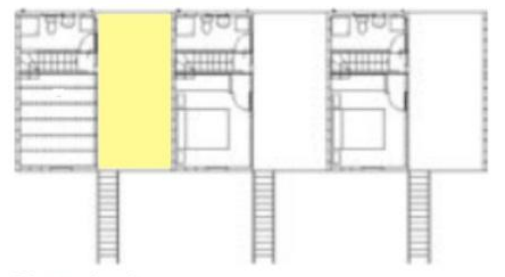

(c)

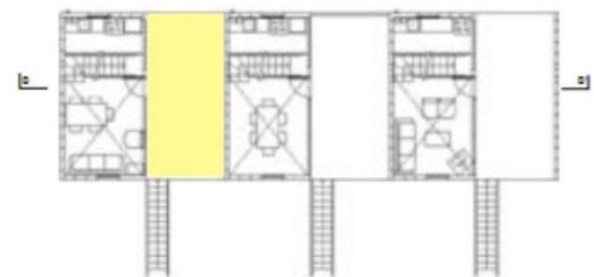

Planta piso 2

(b)

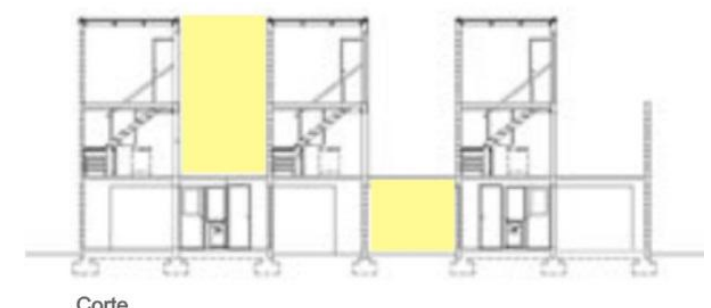

(d)

Figura 15 -Conjunto residencial Quinta Monroy, Iquique, Chile. Projeto das habitações com ênfase nas áreas das possíveis ampliações: $(a, b, c)$ plantas; e (d) corte Fonte: Aravena et al. (2004). 


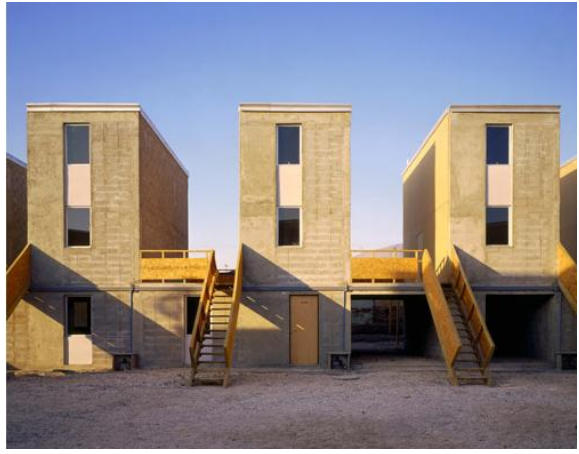

(a)

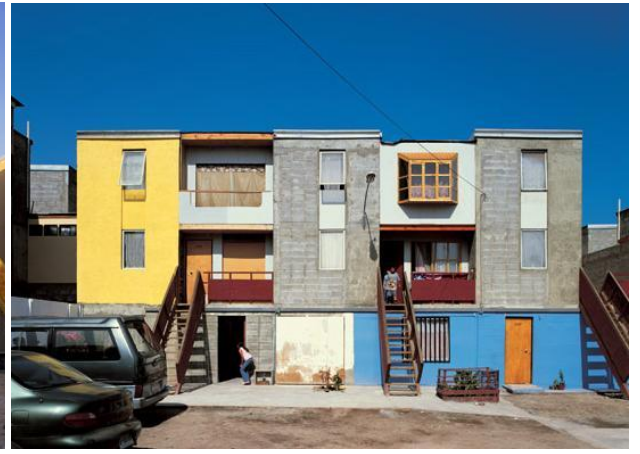

(b)

Figura 16 - Conjunto residencial Quinta Monroy, Iquique, Chile: (a) fachada original, sem intervenções; e (b) fachada já ocupadas, com intervenções dos moradores

Fonte: Aravena et al. (2004).

Propostas da Elemental, como o Conjunto Quinta Monroy, visam projetos embrionários com o conceito de "meia casa bem feita", em contraposição a uma "casa inteira mal construída". Entendem que as partes de maior responsabilidade da construção (fundações, estrutura, cobertura e instalações) devem ser feitas por empresas especializadas, desde o início. O acabamento do espaço embrião mais as ampliações podem ser feitas depois pelo morador, de forma muito facilitada. ${ }^{9}$

Deve-se destacar nos projetos da empresa chilena, propostos para vários países, que a direção das expansões, nunca é para frente. Expande-se lateralmente uma largura equivalente à metade da fachada final e também para os fundos. "Para evitar a deterioração típica das expansões autoconstruídas, o projeto já prevê o cenário final da casa." (HORTA, 2009).

Prever ampliação para uma garagem ou espaço de trabalho. A criação de garagem e espaço de trabalho são modificações registradas com grande frequência. A reserva de um espaço para abrigar pelo menos um automóvel e um espaço produtivo é obrigatória, lembrando que para este segundo, um acesso independente é importante. A reserva de espaços, de modo geral, é uma das estratégias apresentadas por Paiva (2002).

\footnotetext{
${ }^{9} \mathrm{O}$ método de habitação-embrião da Elemental, a partir de 2001, obteve muito êxito e apoio no Chile. Mas é interessante comentar que naquele país, propostas anteriores de espaços flexíveis, adaptáveis às necessidades e possibilidades do usuário, não tinham encontrado sustentação. É o caso do Programa de Habitação Progressiva (PVP), uma novidade lançada em 1991 para pequenas cidades, mas que praticamente desapareceu por volta da metade dos anos 1990. Sugranyes (2006) explica que o PVP nunca foi bem aceito pela maioria das empresas de construção que atuavam no setor de habitação social, devido aos menores ganhos financeiros ao se considerar uma relação de muita implementação de infraestrutura e pouco volume de construção. Havia também a justificativa de que não havia terrenos disponíveis que admitissem menores investimentos.
}

Posicionar o banheiro em local estratégico. O banheiro deve estar localizado em posição transversal ao eixo longitudinal da casa, de forma a beneficiar as ampliações (PALERMO, 2009). Ou seja, melhor que o banheiro seja posicionado em uma das laterais da casa, de preferência na lateral onde não haverá ampliação (evitando o que foi mostrado à Figura 8, anteriormente). E mesmo que o banheiro fique aos fundos, o importante é que a janela do mesmo fique voltada para a lateral.

\section{Esquadrias e aberturas}

Posicionar estrategicamente a esquadria de cada cômodo. A posição da esquadria de cada cômodo deve ser posicionada de tal forma a não ter que ser transferida no caso de ampliações. É também muito racional colocar as janelas em locais onde está planejada a colocação de futuras portas, aproveitando assim a verga existente e reaproveitando a esquadria no novo cômodo criado.

Evitar variações no tamanho das janelas e portas. Para obter mais flexibilidade, deve-se evitar expressões de funcionalidade das peças nas paredes externas, assim como, extremas variações nos tamanhos das janelas (RABENECK; SHEPPARD; TOWN, 1974). Projetar duas janelas menores é mais eficiente do que uma grande (embora tenha maior custo inicial), especialmente em cômodos onde se prevê uma futura divisão. Palermo (2009) defende a uniformização das portas em $80 \mathrm{~cm}$ de largura, inclusive do banheiro, o que facilita a adequação da habitação para acessibilidade.

Prever comunicações adicionais entre os cômodos. Como já foi comentado, cômodos com mais de uma porta podem assumir outras funções, tornando-se multifuncionais. A reversibilidade por meio de portas adicionais não é comum nos 
projetos brasileiros, mas constitui uma forte estratégia de flexibilidade.

Adotar porta adicional ou sistemática de paineljanela. Portas extras metálicas com vidro basculante podem ser colocadas em posições estratégicas da planta, mostrando de forma clara o sentido de expansão da casa. Tais portas podem ser usadas sempre fechadas, funcionando muito mais como janela, e removidas (ou não) quando a ampliação for realizada. Alguns sistemas construtivos podem prever painéis-janela com a mesma finalidade. Além de induzir e mostrar o sentido das expansões, estas portas ou painéisjanelas provisórios e com vergas, facilitam as modificações, evitando quebras desnecessárias que podem danificar as paredes. É uma solução importante, sobretudo em construções com alvenaria estrutural.

\section{Cobertura}

Definir a altura da cumeeira, adequada às ampliações. $\mathrm{O}$ desenho do telhado original é imprescindível na habitação evolutiva. Este estudo deve ser feito no momento da concepção do projeto-embrião, simulando as ampliações mais prováveis de ocorrer, principalmente aquelas cujo sentido de expansão é claramente definido. Neste caso, a cumeeira da casa embrião deve ser mais alta. (Figura 17). No entanto, se a cumeeira não puder ficar mais elevada, que pelo menos fique no mesmo sentido de expansão natural da moradia.

Permitir a criação de novas águas sem afetar a funcionalidade. As águas dos novos espaços não podem afetar as condições de habitabilidade e funcionalidade da construção inicial. Os projetos com flexibilidade planejada devem evitar a redução da iluminação e ventilação da parte embrionária, além de apresentar concordância geométrica e qualidade estética ao final da ampliação.

A solução da cobertura da parte ampliada proposta na Figura 18 é também bastante questionável. A diferença de declividades pode dificultar o escoamento eficiente das águas de chuva, podendo gerar infiltrações e outras patologias. Além disso, a diferença dos tipos de telha geralmente não fornece um resultado estético satisfatório.

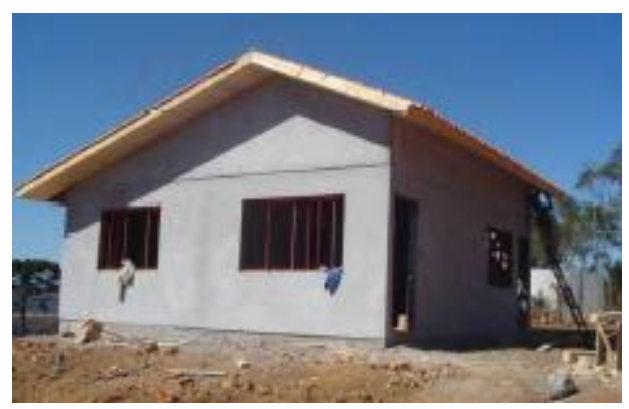

Figura 17 - Casa em fase de construção em Videira, Santa Catarina: o telhado original foi modificado a pedido dos proprietários com a intenção de ampliação futura Fonte: Digiacomo (2004).

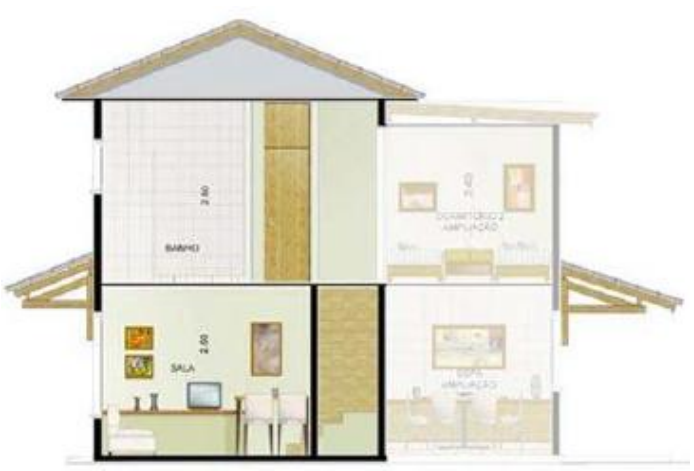

Figura 18 - Casa de dois pisos, Vila Flora: corte mostrando a solução adotada para adequar a cobertura da parte ampliada

Fonte: <www.rossiresidencial.com.br>. 
Para manter a qualidade da ventilação e da iluminação do espaço-embrião uma alternativa está na elevação do pé-direito deste espaço que acabará se tornando central ao fim das ampliações. Esquadrias altas e utilização de lanternins complementam a solução como mostra o exemplo proposto na Figura 19.

\section{Estrutura}

Separar, se possível, estrutura e vedações. A não ser que a edificação seja em alvenaria estrutural, a separação entre estrutura e fechamentos internos permite maior liberdade para as adaptações. Neste caso, a utilização de sistemas de vedação leves torna-se possível ${ }^{9}$.

No caso de construções em alvenaria estrutural, Palermo (2009) sugere a adoção de famílias de blocos de forma a deixar visível ao morador quais são os trechos que não são estruturais, paredes que poderão ser removidas ou receber aberturas.

Preparar a estrutura para receber um ou mais pavimentos. Embora haja um custo adicional para prover o térreo do reforço estrutural necessário, as obras futuras ficam facilitadas, evitando o desconforto de executar tais reforços no interior da parte original da casa quando esta já é habitada.

Preparar a estrutura para receber escadas. Se a escada não for executada de início, deve-se prever ao menos as vigas de apoio na laje, deixando-se o vazio correspondente à projeção da escada. Mesmo os espaços para escadarias externas devem ser reservados ainda na etapa de concepção da residência-embrião. A opção de escadaria externa, independente, pode ser interessante quando da criação de cômodos extras para aluguel ou espaço de trabalho ${ }^{10}$ (escritório, ateliê, etc.).

\section{Instalações}

Dimensionar tubulações de água prevendo aumento de vazão. $\mathrm{O}$ projeto hidráulico deve prever as possibilidades de ampliação, visando a criação de pelo menos mais um banheiro. O cálculo levar em consideração a vazão futura.

Prever paredes hidráulicas permanentes. A parede hidráulica, normalmente utilizada por questões econômicas em moradias populares, representa custo considerável da obra. Sua localização, portanto, deve ser planejada de tal forma que não seja demolida quando houver qualquer adaptação/ampliação futura (PALERMO, 2009). Além disso, os ambientes relacionados à parede hidráulica, as cozinhas e banheiros, devem ter dimensões satisfatórias de modo que seu uso seja confortável para muitos anos, sem necessidade de intervenções (DIGIACOMO, 2004; ARAVENA et al., 2004; HORTA, 2009).

Localizar adequadamente fossa e sumidouro. Estes equipamentos sanitários devem ficar localizados de tal modo que não sejam cobertos pelos novos espaços construídos. Recomenda-se deixá-los próximos da divisa frontal do terreno, em áreas de afastamento obrigatório.

Dimensionar tubulação da fiação para novos circuitos. Recomenda-se estabelecer diâmetros de tubulação que permitam a introdução de fiação adicional, visando o acréscimo de novos circuitos. A previsão de eletrodutos adicionais vazios pode constituir outra alternativa. Assim como no caso do dimensionamento da vazão, a carga futura deve ser estimada. No caso de se adotar a estratégia de junção e desmembramento da habitação, deve-se prever meios de inserir novo quadro de energia, medidores em separado, dentre outras medidas a serem pensadas no momento do projeto.
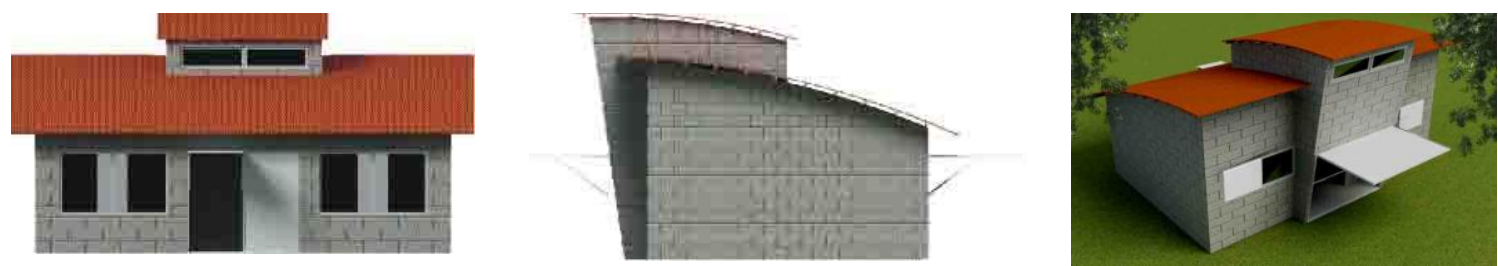

Figura 19 - Projeto “Hab[A]”, do Núcleo de Projetos do Centro Universitário Barão de Mauá, Ribeirão Preto, São Paulo: na torre central estão cozinha, banheiro e área de serviço; os demais espaços ao redor, em formato de $U$, constituem a parte livre ou flexível

Fonte: Villa e Silva (2005).

\footnotetext{
${ }^{10}$ Esta estratégia advém do Movimento Moderno, com os primeiros estudos de Le Corbusier para a Maison Dom-Ino, esquema onde existe uma separação entre estrutura, vedação e cobertura. Essa independência estrutural possibilitava, teoricamente, uma flexibilidade dos interiores. As paredes internas, por não terem função estrutural, poderiam ser modificadas, retiradas e até substituídas por painéis e armários (LINO, 2007).

${ }^{11}$ Normalmente o espaço produtivo fica no piso térreo, deixando a parte residencial nos pisos superiores, como nos projetos canadenses propostos por Friedman $(1997 ; 2002)$. Mas, no caso da HIS unifamiliar evolutiva da qual falamos, a parte superior só virá a ser construída em futura etapa.
} 
Evitar luminárias centrais. Rabeneck, Sheppard e Town (1974) propõem evitar luminárias centrais e outros condicionantes de determinação do espaço. Esta recomendação vale para os ambientes planejados para serem divididos, sendo indicada a adoção de arandelas, ao invés de luminárias de teto.

Localizar interruptores e tomadas em pontos adequados. Além de um projeto corretamente dimensionado, é preciso prever as modificações e ampliações mais prováveis de ocorrer, de tal forma a decidir sobre a posição de interruptores e tomadas. O projeto deve, pelo menos, evitar muitas dificuldades e alterações das localizações inicialmente definidas destes pontos. Esta diretriz, assim como as demais, objetiva adaptações facilitadas e não reformas, com perda de materiais.

Acrescentar pia de lavar extra fora do banheiro. Adotar banheiro compartimentado, ou seja, deixando a bancada de lavatório acessível, cria a versatilidade de uso pela família (PALERMO, 2009). Melhor ainda se for prevista um lavatório adicional localizado em um nicho de parede ou pequeno hall na entrada do banheiro. Representa custo adicional, mas é um componente que propicia utilidade e funcionalidade para as famílias, dado que apenas um banheiro costuma existir na casa-embrião. Em muitos países, o banheiro é dividido em dois módulos independentes: um para banho e outro para o vaso sanitário, possibilitando versatilidade de uso.

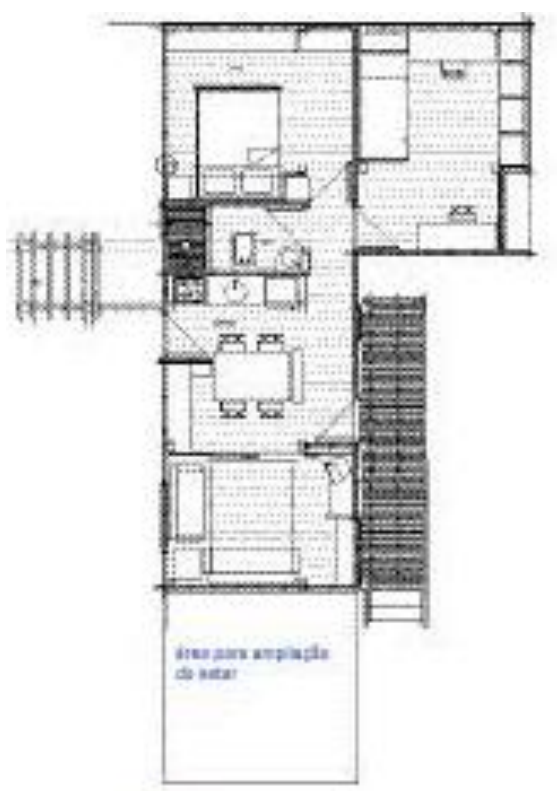

\section{Divisão de ambientes e mobiliário}

Utilizar divisórias desmontáveis elou móveis. As divisórias desmontáveis e/ou móveis são excelentes agentes de integração e separação de ambientes. Galfertti (1997) apresenta vários mecanismos deste tipo, em uma extensa série de casos experimentais. A Figura 20 mostra um exemplo no qual a divisória está entre a copacozinha e a sala de estar que também funciona como quarto. Com a ampliação, a divisória é desmontada e recolocada em outra posição na casa. Mas deve-se ressaltar que, mesmo nos casos em que a área da habitação permanece a mesma, esta estratégia pode ser explorada, permitindo que a planta possa ser modificada.

Evitar excesso de móveis fixos. O uso de móveis fixos, feitos de madeira, alvenaria ou concreto, pode ser uma alternativa para prover mobiliário de baixo custo. No entanto, uma vez que retiram a liberdade do usuário para reorganizar seus espaços, devem ser pouco usados, ou se limitar a locais que dificilmente serão modificados no futuro.

Utilizar móveis para dividir ambientes. É uma estratégia que possibilita integrar e isolar a qualquer tempo, sem depender de construção. Mas não deve passar a imagem de improvisação ao dividir ambientes, daí, é importante utilizar móveis que apresentem acabamento dos dois lados. O uso de estantes vazadas constitui uma alternativa.

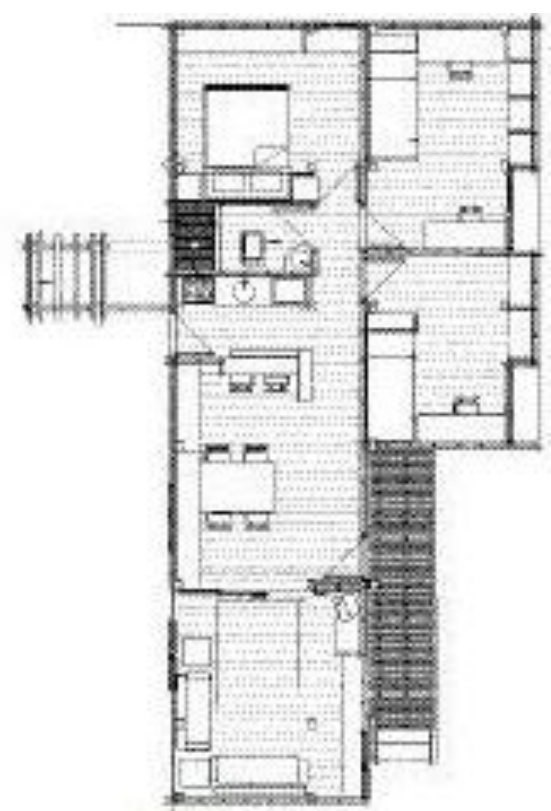

Figura 20 - Habitação em madeira, modulada e ampliável, com a estratégia de divisórias desmontáveis Fonte: Oliveira (2003). 


\section{Terreno e tipologias}

Prever afastamento que permita ampliar para frente. Não é necessário implantar a casa usando o menor recuo permitido. Ou seja, a casa não precisa ser construída muito à frente do terreno, permitindo, assim, planejar ampliações futuras como garagem, varanda, nova sala, espaço produtivo, etc. e ainda manter um jardim.

Adotar terrenos mais largos, se possível. Sempre que possível, adotar lotes mais largos, os quais, segundo Szücs et al. (2000) e Friedman (2002), são mais indicados para as propostas de habitação flexível. Nestes lotes, a casa pode apresentar melhor circulação de ar e maior exposição de luz nas fachadas, como explica Digiacomo (2004). Obviamente as casas podem ser ampliadas em vários sentidos nos lotes mais largos. O principal entrave está mesmo no custo maior da infraestrutura que esta forma de loteamente promove.

Uma alternativa em lotes mais largos poderia ser a geminação das casas, duas a duas ou em fita, o que minimizaria os custos de infraestrutura (PALERMO, 2009). Já Digiacomo (2004) lembra que outras tipologias, como a casa-pátio, por exemplo, também proporcionam projetos flexíveis de forma satisfatória.

\section{Apoio ao usuário}

Fornecer projetos de opções de possíveis ampliações. Mesmo que estejam claros os sentidos de expansão da moradia, é imprescindível que o usuário receba um conjunto de projetos com as ampliações possíveis de serem executadas após a entrega da casa. Esta é uma forma de assessoria técnica para as famílias mais carentes que não podem contratar um arquiteto ou engenheiro.

Criar manual do usuário da habitação. Além das possibilidades de ampliação, o manual do usuário da habitação deve conter os projetos e especificações técnicas da construção e recomendações para manutenção, principalmente. Deve apresentar linguagem clara e objetiva e enfatizar as ilustrações.

\section{Estratégias e princípios relacionados com as diretrizes propostas}

O Quadro 2 relaciona todas as diretrizes e disposições técnicas que foram descritas, vinculando-as com as estratégias e princípios apresentados no método.
A estratégia G, "Desenho da arquitetura", proposta por Digiacomo (2004) foi a mais frequente, uma vez que agrupa estratégias como planta livre, preparação da casa para as possibilidades de expansão vertical, lateral e para os fundos, união de unidades, ambientes reversíveis, ambientes multiuso, alternância entre isolar e integrar e baixa hierarquia (ambientes com pouca variabilidade de tamanho entre si). A estratégia $\mathrm{H}$, "Alteração da área útil e dos limites da construção”, proposta por Paiva (2002) tem pontos comuns com a estratégia $\mathrm{G}$ e, por esta razão aparece também com mais frequência. As estratégias $\mathrm{G}$ e $\mathrm{H}$ envolvem o aspecto evolutivo em sua forma mais básica, ou seja, a ampliação física.

Já o grupo de estratégias D, "Espaços neutros e polivalência de usos", aparece apenas duas vezes. Note-se que estas estratégias envolvem justamente o contrário daquilo que é trivial, ou seja, determinar funções. A maioria das estratégias, mesmo visando flexibilizar, acaba seguindo na direção de definir usos e comportamentos. Vale citar as críticas feitas por Kapp (2007) ao modo de projetar herdado, ou seja, a segmentação do espaço da moradia em áreas social, íntima e de serviço, cômodos monofuncionais, espaços perenes. Segundo Kapp (2007), “[...] o que se projeta não são os espaços e suas qualidades, mas invólucros perfeitos para pessoas e eventos inexistentes[...]".

Espaços neutros e multifuncionais poderiam ser mais utilizados nos projetos residenciais. Rabeneck, Sheppard e Town (1974) afirmam que projetos adaptáveis poderiam ser construídos com áreas muito pouco acima dos padrões utilizados nos projetos de base funcional. Ou seja, há os que defendem a ideia de que se pode ser mais eficiente na criação de ambientes multiuso, simplesmente com a provisão de mais espaço. Outros autores, como Callado (1995), ao defender a baixa hierarquia, e Hertzberger (1999), ao se referir à polivalência, apoiam a neutralidade.

O Quadro 2 apresenta também os princípios que contribuem para a adaptabilidade correspondentes a cada diretriz proposta. A versatilidade é o principio que mais vezes aparece (14), seguido da superprovisão (13), da upgradability (12) e da independência (11). A durabilidade, relacionada 9 vezes, foi aqui tratada não somente em seu sentido usual de ciclo de vida dos materiais, mas também quanto ao potencial dos espaços para prover usos mais duradouros, que evitem reformas e demolições. 


\begin{tabular}{|c|c|c|c|}
\hline Grupo & Diretriz & Estratégias & Princípios \\
\hline $\begin{array}{l}\text { Arranjo espacial } \\
\text { quanto à forma e } \\
\text { dimensão dos } \\
\text { cômodos }\end{array}$ & $\begin{array}{l}\text { 1. Prover cômodos neutros e sem extremos de tamanho } \\
\text { 2. Prover cômodos ou ambientes multiuso } \\
\text { 3. Prever a possibilidade de nova posição de porta no banheiro } \\
\text { 4. Prever, se possível, espaço de refeições maior nas cozinhas } \\
\text { 5. Estudar a opção de usar ou não corredores dentro da unidade }\end{array}$ & $\begin{array}{l}\text { D, H, I } \\
\text { H, I } \\
\text { C, G } \\
\text { D, H, I } \\
\text { C }\end{array}$ & $\begin{array}{l}5,6,8,9 \\
6,9 \\
2,6 \\
6,8 \\
9\end{array}$ \\
\hline $\begin{array}{l}\text { Arranjo espacial } \\
\text { quanto ao sentido de } \\
\text { expansão }\end{array}$ & $\begin{array}{l}\text { 6. Deixar claro o sentido de expansão da moradia } \\
\text { 7. Prever ampliação para uma garagem ou espaço de trabalho } \\
\text { 8. Posicionar o banheiro em local estratégico }\end{array}$ & $\begin{array}{l}\text { E, H, I } \\
\text { E, F, H, I } \\
\text { H, I }\end{array}$ & $\begin{array}{l}2 \\
2,6,8 \\
5\end{array}$ \\
\hline $\begin{array}{l}\text { Esquadrias e } \\
\text { aberturas }\end{array}$ & $\begin{array}{l}\text { 9. Posicionar estrategicamente a esquadria de cada cômodo } \\
\text { 10. Evitar variações no tamanho das janelas } \\
\text { 11. Prever comunicações adicionais entre os cômodos } \\
\text { 12. Adotar porta adicional ou sistemática de painel-janela }\end{array}$ & $\begin{array}{l}\text { B, F, I } \\
\text { B, F, I, J } \\
\text { C, G } \\
\text { C, F, G, H, I, J }\end{array}$ & \begin{tabular}{|l|}
5 \\
6,9 \\
$2,6,8$ \\
$5,6,8$ \\
\end{tabular} \\
\hline Cobertura & $\begin{array}{l}\text { 13. Definir a altura da cumeeira, adequada às ampliações } \\
\text { 14. Permitir a criação de novas águas sem afetar a funcionalidade }\end{array}$ & \begin{tabular}{|l} 
F, H, I \\
F, H, I
\end{tabular} & $\begin{array}{l}1,2,8 \\
1,2\end{array}$ \\
\hline Estrutura & $\begin{array}{l}\text { 15. Separar, se possível, estrutura e vedações } \\
\text { 16. Preparar a estrutura para receber um ou mais pavimentos } \\
\text { 17. Preparar a estrutura para receber escadas (expansão vertical) }\end{array}$ & $\begin{array}{l}\text { E, F, I } \\
\text { E, F, H, I } \\
\text { C, E, H, I }\end{array}$ & $\begin{array}{l}1,6,9 \\
2,6,8 \\
2,8\end{array}$ \\
\hline Instalações & $\begin{array}{l}\text { 18. Dimensionar tubulações de água prevendo aumento de vazão } \\
\text { 19. Prever paredes hidráulicas permanentes } \\
\text { 20. Localizar adequadamente fossa e sumidouro } \\
\text { 21. Dimensionar tubulação da fiação para inserção de novos circuitos } \\
\text { 22. Evitar luminárias centrais } \\
\text { 23. Localizar interruptores e tomadas em pontos adequados } \\
\text { 24. Acrescentar pia de lavar extra fora do banheiro }\end{array}$ & $\begin{array}{l}\text { A } \\
\text { A, H, I, J } \\
\text { A, H, I } \\
\text { A } \\
\text { A, B, H, I } \\
\text { A, B, H, I } \\
\text { A, H, I }\end{array}$ & $\begin{array}{l}2,5,8 \\
1,5,7 \\
5,7 \\
1,2,5,7,8 \\
1,7 \\
1,7 \\
6,8\end{array}$ \\
\hline $\begin{array}{l}\text { Divisão de } \\
\text { ambientes e } \\
\text { mobiliário } \\
\end{array}$ & $\begin{array}{l}\text { 25. Utilizar divisórias desmontáveis e/ou móveis } \\
\text { 26. Evitar excesso de móveis fixos } \\
\text { 27. Utilizar móveis para dividir ambientes }\end{array}$ & $\begin{array}{l}\text { B, E, I, J } \\
\text { A, B, E, I } \\
\text { A, B, E, I }\end{array}$ & $\begin{array}{l}1,6,9 \\
1,9 \\
1,6,9 \\
\end{array}$ \\
\hline Terreno e tipologias & $\begin{array}{l}\text { 28. Prever afastamento que permita ampliar para frente } \\
\text { 29. Adotar terrenos mais largos, se possível }\end{array}$ & $\begin{array}{l}\text { F, G, H, I } \\
\mathrm{H}, \mathrm{I}\end{array}$ & $\begin{array}{l}2,6 \\
8\end{array}$ \\
\hline Apoio ao usuário & $\begin{array}{l}\text { 30. Fornecer projetos de opções de possíveis ampliações } \\
\text { 31. Criar manual do usuário da habitação. }\end{array}$ & $\begin{array}{l}\text { A, E, H, I, K } \\
\text { A, E, H, I, K }\end{array}$ & $\begin{array}{l}2,4,8 \\
4,5\end{array}$ \\
\hline
\end{tabular}

Quadro 2 - Relação das diretrizes para projeto da habitação social evolutiva unifamiliar com as correspondentes estratégias e princípios (ou características) que contribuem para a adaptabilidade Legenda:

Estratégias (e frequência)

A - Concepções de equipamentos, instalações e mobiliário (11)

B - Alteração da compartimentação (07)

C - Forma de circulação (05)

D - Espaços neutros e polivalência de usos (02)

E - Concepção estrutural (10)

F - Concepção das fachadas (09)

G - Localização e número de acessos (04)

H - Alteração da área útil e dos limites da construção (20)

I - Desenho da arquitetura (26)

$\mathrm{J}$ - Estratégias de padronização de componentes (04)

$\mathrm{K}$ - Manual de instruções (02)
Princípios (e frequência)

1 - Independência (10)

2 - Upgradability (12)

3 - Compatibilidade de ciclos de vida $\left({ }^{*}\right)$

4 - Informação (02)

5 - Durabilidade (09)

6 - Versatilidade (14)

7 - Facilidade de acesso às instalações (05)

8 - Redundância (superprovisão) (13)

9 - Simplicidade (08)

(*) Observação: não considerado nas análises 
No que se refere à adaptabilidade nas edificações, Russel e Moffatt (2001) ressaltam que a independência é o princípio mais importante para promover adaptabilidade. Entre os primeiros pesquisadores que reconheceram a importância da independência no projeto estava N. J. Habraken, da Holanda, que expôs as vantagens do conhecido conceito de "Open Building". É muito provável que a Teoria de Suportes ${ }^{12}$ de Habraken seja a base de maior robustez dentro da temática da flexibilidade habitacional.

A proposta da equipe Elemental, na cidade de Iquique, Chile, muito provavelmente se inspirou na Teoria de Suportes de Habraken. É fornecido ao usuário tudo que é tecnicamente mais difícil de se produzir, como a estrutura, os principais fechamentos, a cobertura e a infraestrutura de instalações. A obra foi entregue ao usuário sem acabamentos e com o espaço equivalente a apenas $30 \mathrm{~m} 2$ (25 a $35 \%$ menor que as casas populares típicas brasileiras).

Outro projeto similar é a proposta da Growth Homes, de Hertzberger, em Almere, Holanda (DIGIACOMO, 2004). São casas em fita, onde uma das laterais é deixada completamente vazia. É relatado no site do arquiteto que alguns moradores colocaram coberturas de vidro, outros construíram mais área de quartos ou sala.

\section{Aspectos relacionados aos custos para promover flexibilidade}

Uma questão sempre relevante é: quanto custa promover a flexibilidade? Embora não seja objetivo deste trabalho avaliar custos, dois aspectos merecem ser comentados: a influência da geometria e a superprovisão.

As plantas consideradas "prontas", não flexíveis, tendem a apresentar maiores índices de compacidade $^{13}$ e menores relações entre os planos

\footnotetext{
${ }^{12}$ A obra de John Habraken, "Supports: an alternative to mass housing" (1972), propõe que os processos do projeto e da construção da habitação contemplem dois momentos de tomada de decisão: individual e coletiva, que conformam a Teoria de Suportes. Como explicado na página do Grupo Morar de Outras Maneiras, da UFMG (www.mom.arq.ufmg.br), os "suportes", que não devem ser confundidos com o esqueleto do edifício, são construcões que abrigam o conjunto de infraestrutura. Em oposição às moradias produzidas em massa, os suportes precisam ser estruturas duráveis cujas formas permitam o inesperado. A característica chave dos chamados "Open Buildings" é a separação entre "recheio" (tudo que o usuário precisa para ocupar definitivamente a unidade habitacional: divisórias, esquadrias, forro, pisos, arranjo dos cômodos, pontos das instalações) e "suportes" (condição dada ao usuário para que ele ocupe uma unidade habitacional - o sistema estrutural independente mais a infraestrutura constituída por abastecimento de água e energia, esgotamento sanitário, telefonia, circulação e segurança, lixo e saídas de emergência).

${ }^{13}$ Relação entre o perímetro de um círculo de área igual a do projeto avaliado e o perímetro externo deste mesmo projeto,
}

verticais (paredes) por unidade de área construída. Por sua vez, os projetos considerados "incompletos" (como as plantas em formato de L), projetados para evoluir posteriormente, já apresentam menor índice de compacidade e maior densidade de paredes. Mas trata-se tão somente de um custo por metro quadrado um pouco maior, mas que diminui após a realização das ampliações.

O segundo aspecto do custo da flexibilidade é a superprovisão, termo técnico que designa as previsões extras no projeto. Mas é importante lembrar que nos financiamentos os custos se diluem ao longo dos anos, de forma que itens mais onerosos podem ser incluídos nos mesmos. Na HIS, nos casos em que existem subsídios, estes poderiam cobrir os custos iniciais mais elevados, uma estratégia para garantir as ampliações futuras.

A análise de custos, quando considerada apenas a etapa inicial de projeto e construção, identificará os acréscimos influenciados pela geometria da planta e pela superprovisão. No entanto, é importante se avaliar o custo global da habitação, verificando os prováveis ganhos provenientes da flexibilidade, seja pela simplicidade e facilidade de promover as adaptações e ampliações, sem desperdícios, seja pela própria valorização do imóvel pela melhor qualidade técnica e arquitetônica da obra final, evitando-se os típicos "puxados".

Por fim, foi enfatizado nos projetos evolutivos que as ampliações devem ocorrer sem que nenhuma das paredes com instalações (parede hidráulica, por exemplo), que têm custo maior de construção tenham que sofrer intervenções. Para que isto ocorra deve-se recorrer à estratégias que permitam que as futuras intervenções na habitação sejam efetuadas de modo que só haja incremento da qualidade. Não há sentido em grandes mudanças ou reformas e mesmo demolições de partes de uma casa que foi financiada para uma família de baixa renda. Todas as estratégias devem ser voltadas tão somente para melhorias e acréscimos.

\section{Considerações finais}

Infelizmente, casas arquitetonicamente rígidas no que se refere à possibilidade de modificar, são uma realidade da produção habitacional, não somente no caso brasileiro. Existe ainda o risco de este modelo ser ainda mais reforçado, ao se adotar, de forma indiscriminada, sistemas construtivos industrializados fechados. Todavia, se bem utilizada, a industrialização pode trazer diversos

dada em porcentagem. Assim, o círculo tem Índice de Compacidade (Ic) igual a $100 \%$ e o quadrado, $88,6 \%$. 
benefícios, combinando ou não com os sistemas tradicionais de construção.

Os projetos típicos, em sua grande maioria, não encontram facilidades para adaptação com qualidade e baixo custo. Nem, tampouco, nestes casos, se pode responsabilizar o usuário por adaptações e ampliações de geometria e estética ruim, uma vez que o projeto original não contempla abertura para intervenções posteriores adequadas e estéticas. Por outro lado, o trabalho dos arquitetos não é tão simples, pois é preciso pensar um embrião que não pareça uma obra inacabada e ao mesmo tempo imaginar as casas ampliadas sem que as partes expandidas não pareçam construções improvisadas.

Neste trabalho foram descritas várias dificuldades que costumam ocorrer quando o usuário deseja promover modificações em sua moradia, sobretudo as ampliações que, se mal elaboradas comprometem a estética da casa como um todo. Viu-se que as ampliações necessitam de acompanhamento técnico, visando qualidade arquitetônica.

Não há dúvida que o conjunto de orientações, aqui organizado, pode promover projetos mais flexíveis, mas este não deve ser considerado um levantamento definitivo. Mais estudos são sugeridos para identificar outras diretrizes. Há de se considerar, também, que as casas modificadas aqui comentadas referem-se a casos matogrossenses e alguns poucos exemplos catarinenses, o que limita uma possível generalização das características observadas. Isto sem falar que se focalizou aqui apenas a moradia unifamiliar, dentre várias tipologias possíveis para HIS.

No estudo foi também possível identificar para cada diretriz, as estratégias e os princípios correspondentes. Uma conclusão é que as estratégias (e as próprias diretrizes) estão fortemente relacionadas entre si, de tal forma que não podem ser consideradas pontualmente nos projetos. Já os princípios envolvidos mantém uma distinção mais clara entre si, sendo todos relevantes quando o objetivo é projetar uma habitação evolutiva.

Casas embrião, para construção e acabamento em etapas, são sugeridas, mas devem ser planejadas para que as ampliações não sejam tão livres ao ponto de comprometer a qualidade estética da casa ampliada. Neste caso, são recomendadas ampliações para os lados, como visto nos exemplos chileno e holandês descritos, além de necessária assistência técnica.

Apesar de ser oferecido um conjunto organizado de soluções, propiciando projetos planejados para serem adaptáveis (interna e externamente), há o risco de se obter ganhos apenas parciais, o que, de alguma forma, já seria benéfico. As estratégias e princípios que visam produções evolutivas devem estar sempre presentes na concepção, seja para adequar tipologias tradicionais, seja para pensar novas possibilidades de espaço habitacional. Novos desenhos para o espaço doméstico devem ser constantemente desenvolvidos e avaliados. Ressalte-se também que o objetivo de produzir habitações flexíveis, liga-se à questão da sustentabilidade.

É interessante perceber que muitos ganhos na qualidade da habitação podem ser obtidos com decisões simples na fase do projeto, tanto no que se refere à definição dos espaços como nas tecnologias adotadas. Realmente, graus leves de flexibilidade e de tecnologia são suficientes para gerar mais qualidade para a habitação.

\section{Referências}

ALBERS, M.; HENZ, A.; JACOB, U. Wohnform und Wohnungsform. Wohnungen für unterschiedliche Haushaltformen [Apartamentos para vários tipos de organização familiar]. Werk, Bauen und Wohnen, Zuerich, v.76/43, n. 5, p.6073, 1989.

ALONSO, F. The Benefits of Building BarrierFree: a contingent valuation of accessibility as an attribute of housing. European Journal of Housing Policy, v. 2, n. 1, p. 25-44, 2002.

ARAVENA, A. et al. Quinta Monroy. ARQ, Santiago, v. 57, p. 30-33, jul. 2004.

ASSOCIAÇÃO BRASILEIRA DE CIMENTO PORTLAND. Casa 1.0: bairro saudável, população saudável. São Paulo: ABCP, 2002. 88 p. Manual técnico.

BAUWENS, L.; CAMPBELL, A. Spaces for Living: how to create multifunctional rooms for today's homes. New York: Clarkson Potter, 1999. $160 \mathrm{p}$.

BITTENCOURT, R. M.; SILVA, J. S. Avaliação das Reformas e Empliações das Casas Populares da Cohab-Guaratinguetá, SP. In: CONGRESSO TÉCNICO-CIENTÍFICO DE ENGENHARIA CIVIL, 1996, Florianópolis. Anais... Florianópolis: UFSC, 1996. v. 2, p. 315-324. 
BRANDÃO, D. Q. Diversidade e Potencial de Flexibilidade de Arranjos Espaciais de Apartamentos: uma análise do produto imobiliário brasileiro. 2002. 443 f. Florianópolis. Tese (Doutorado em Engenharia de Produção) Programa de Pós-Graduação em Engenharia de Produção, Universidade Federal de Santa Catarina, Florianópolis, 2002.

BRANDÃO, D. Q. Flexibilidade, Variabilidade e Participação do Cliente em Projetos

Residenciais Multifamiliares: conceitos e formas de aplicação em incorporações. 1997. 245 f.

Florianópolis. Dissertação (Mestrado em Engenharia Civil) - Programa de Pós-Graduação em Engenharia Civil, Universidade Federal de Santa Catarina, Florianópolis, 1997.

BRANDÃO, D. Q. Habitação Social Evolutiva: aspectos construtivos, diretrizes para projetos e proposição de arranjos espaciais flexíveis. Cuiabá: CEFETMT, 2006. Manual técnico.

BRANDÃO, D. Q. O Conceito de Adaptabilidade na Habitação de Interesse Social: da carência de espaço às tendências atuais utilizando espaços multiuso. In: CONGRESSO BRASILEIRO SOBRE HABITAÇÃO SOCIAL, 2003, Florianópolis. Anais... Florianópolis: UFSC, 2003. 1 CD-ROM.

BRANDÃO, D. Q. O Porquê das Modificações Promovidas pelo Usuário em Sua Moradia: classificação e discussão de razões, com base no significado multidimensional e dinâmico da habitação. In: SEMINÁRIO MATO-GROSSENSE DE HABITAÇÃO DE INTERESSE SOCIAL, 2005, Cuiabá. Anais... Cuiabá: CEFETMT, EdUFMT, 2005. 1 CD-ROM, p. 249-264.

CALLADO, J. The Architect's Perspective. Urban Studies, Essex, v. 32, n. 10, p. 1665-1677, 1995.

CAMPANHOLO, J. L. Construção Personalizada: uma realidade do mercado. Téchne, São Paulo, v. 41, p. 63-66, jul./ago. 1999.

CARVALHO, L.O. Análise Qualitativa dos Custos Decorrentes da Personalização de Unidades Residenciais. 2004. Florianópolis. Dissertação (Mestrado em Engenharia Civil) Programa de Pós-Graduação em Engenharia Civil, Universidade Federal de Santa Catarina, Florianópolis, 2004.

CAVALCANTI, L. Quando o Brasil Era Moderno: guia de arquitetura 1928-1960. Rio de Janeiro: Aeroplano, 2001.
CÍRICO, L. A. Por Dentro do Espaço Habitável: uma avaliação ergonômica de apartamentos e seus reflexos nos usuários. 2001. 156 f. Florianópolis. Dissertação (Mestrado em Engenharia de Produção) - Programa de Pós-Graduação em Engenharia de Produção, Universidade Federal de Santa Catarina, Florianópolis, 2001.

DADAM, T.; BRANDÃO, D. Q. Descrição, Análise e Discussão das Modificações de Projeto na Avaliação Pós-Ocupação de Casas de SoloCimento no Município de Itiquira, Mato Grosso. In: SEMINÁRIO MATO-GROSSENSE DE HABITAÇÃO DE INTERESSE SOCIAL, 2005, Cuiabá. Anais... Cuiabá: CEFETMT, EdUFMT, 2005. 1 CD-ROM, p. 227-237.

DESPRÉS, C. The Meaning of Home: literature review and directions for future research and theoretical development. Journal of Architectural and Planning Research, Chicago, v. 8, n. 2, p. 96-115, summer 1991.

DIGIACOMO, M. C. Estratégias de Projeto para Habitação Social Flexível. 2004. 163 f. Florianópolis. Dissertação (Mestrado em Arquitetura) - Programa de Pós-Graduação em Arquitetura e Urbanismo, Universidade Federal de Santa Catarina, Florianópolis, 2004.

FINKELSTEIN, C. W. Flexibilidade na Arquitetura Residencial: um estudo sobre o conceito e sua aplicação. 2009. Porto Alegre. Dissertação (Mestrado em Arquitetura) Programa de Pós-Graduação em Arquitetura, Universidade Federal do Rio Grande do Sul, Porto Alegre, 2009.

FRIEDMAN, A. Design for Flexibility and Affordability: learning from the post-war home. Journal of Architectural and Planning Research, Chicago, v. 14, n. 2, p. 150-170, summer 1997.

FRIEDMAN, A. The Adaptable House: designing homes for change. Toronto: Mc GrawHill, 2002.

GALFERTTI, G. G. Model Apartments: experimental domestic cells. Barcelona: Gustavo Gili, 1997.

HABRAKEN, N. J. Supports: an alternative to mass housing. London: The Architectural Press, 1972.

HERTZBERGER, H. Lições de Arquitetura. São Paulo: Martins Fontes, 1999. 272 p.

HORTA, M. Puxadinho Formalizado. Arquitetura e Urbanismo, São Paulo, v. 24, n. 186, p. 44-49, set. 2009. 
KAPP, S. Síndrome do Estojo. In: COLÓQUIO DE PESQUISAS EM HABITAÇÃO, 4., 2007, Belo Horizonte. Anais... Belo Horizonte: EAUFMG, Grupo Morar de Outras Maneiras, 2007.

LINO, S. F. A Obra de Eladio Dieste: flexibilidade e autonomia na produção arquitetônica. In: COLÓQUIO DE PESQUISAS EM HABITAÇÃO, 4., 2007, Belo Horizonte. Anais... Belo Horizonte: EAUFMG, Grupo Morar de Outras Maneiras, 2007.

MARROQUIM, F. M. G; BARBIRATO, G. M. Flexibilidade Espacial em Projetos de Habitações de Interesse Social. In: COLÓQUIO DE PESQUISAS EM HABITAÇÃO, 4., 2007, Belo Horizonte. Anais... Belo Horizonte: EAUFMG, Grupo Morar de Outras Maneiras, 2007.

MOSCHEN, P.D.C. Uma Metodologia para Personalização de Unidades Habitacionais em Empreendimentos Imobiliários Multifamiliares. 2003. 193 f. Florianópolis. Dissertação (Mestrado em Engenharia de Produção) - Programa de PósGraduação em Engenharia de Produção, Universidade Federal de Santa Catarina, Florianópolis, 2003.

OLIVEIRA, C.F. Autoconstrução em Madeira. 2003. São Carlos. Dissertação (Mestrado em Arquitetura) - Programa de Pós-Graduação em Arquitetura, Escola de Engenharia de São Carlos, Universidade de São Paulo, São Carlos, 2003.

PALERMO, C. et al. Habitação Social: uma visão projetual. In: COLÓQUIO DE PESQUISAS EM HABITAÇÃO, 4., 2007, Belo Horizonte. Anais... Belo Horizonte: EAUFMG, 2007.

PALERMO, C. Sustentabilidade Social do Habitar. Florianópolis: Edição da autora, 2009. 96 p.

PADUART, A. et al. Transforming Cities: introducing adaptability in existing residential buildings through reuse and disassembly strategies for restrofitting. 2009. Disponível em: <http://www.cibworld.nl/home/index.html>. Acesso em: 13 abr. 2010.

PAIVA, A. L. S. A. Habitação Flexível: análise de conceitos e soluções. 2002. Lisboa. Dissertação (Mestrado em Arquitetura) - Faculdade de Arquitetura, Universidade Técnica de Lisboa, Lisboa, 2002.
PAYERAS, D. R. Levantamento dos Resíduos Sólidos Gerados pela Personalização Não Planejada de Apartamentos: estudo de caso em Porto Alegre, RS. 2005. Porto Alegre. Dissertação (Mestrado Profissionalizante em Engenharia) Escola de Engenharia, Universidade Federal do Rio Grande do Sul, Porto Alegre, 2005.

PEDRO, J. A. C. B. O. Definição e Avaliação da Qualidade Arquitectónica Habitacional. 2000.

392 f. Lisboa. Tese (Doutorado em Arquitectura) Faculdade de Arquitectura, Universidade do Porto, Lisboa, 2000.

RABENECK, A.; SHEPPARD, D.; TOWN, P. Housing Flexibility/Adaptability? Architectural Design, London, v. 49, p. 76-90, feb. 1974.

REIS, A. T. L. Ambientes Residenciais: alterações espaciais, comportamentos e atitudes dos moradores. In: ENCONTRO NACIONAL DE TECNOLOGIA DO AMBIENTE CONSTRUÍDO, 8., 2000, Salvador. Anais... Salvador: ANTAC, 2000. 1 CD-ROM.

REIS, A. T. L. Avaliação de Alterações Realizadas pelo Usuário no Projeto Original da Habitação Popular. In: ENCONTRO NACIONAL DE TECNOLOGIA DO AMBIENTE CONSTRUÍDO, 6., 1995, Rio de Janeiro. Anais... Rio de Janeiro: ANTAC, 1995. v. 1, p. 319-324.

RODRIGUES, A. C.; BRANDÃO, D. Q. Projeto XIV: uma proposta para maximização do potencial de ampliabilidade residencial a partir de um espaço-embrião de 20 metros quadrados. In: SEMINÁRIO MATO-GROSSENSE DE HABITAÇÃO DE INTERESSE SOCIAL, 2005, Cuiabá. Anais... Cuiabá: CEFETMT, EdUFMT, 2005. 1 CD-ROM, p. 291-304.

ROSSO, T. Racionalização da Construção. São Paulo: USP/FAU, 1980. 300 p.

RUSSEL, P.; MOFFATT, S. Assessing the Adaptability of Buildings. In: ENERGYRELATED ENVIRONMENTAL IMPACT OF BUILDINGS, 31., 2001. Proceedings... 2001. 13 p.

SCHNEIDER, T.; TILL, J. Flexible Housing: Opportunities and Limits. Theory, v. 9, n. 2, p. 157-166, 2005.

SUGRANYES, A. Social Housing Policy in Chile Since 1980: actors and products. 2006. 184 f. Tese (Doutorado), Universidade Tecnológica de Delft, 2006.

SKIDMORE, L.; OWINGS, N. A.; MERRIL, J. O. The New House 194X ...: 12, flexible space. The Architectural Forum, p.100-103, 1942. 
SZÜCS, C. P. Flexibilidade Aplicada ao Projeto da Habitação Social. In: ENCONTRO NACIONAL DE TECNOLOGIA DO AMBIENTE

CONSTRUÍDO, 7., 1998, Florianópolis. Anais... Florianópolis: ANTAC, 1998. v. 1, p. 621-628.

SZÜCS, C.P. et al. Habitação de Interesse

Social: flexibilidade do projeto, contextualização das soluções. Florianópolis: UFSC, 2000.

Relatório Técnico.

SZÜCS, C.P. et al. Sistema Stella-UFSC:

avaliação e desenvolvimento de sistema construtivo em madeira de reflorestamento voltado para programas de habitação social. Florianópolis: UFSC, set. 2004. Relatório final de pesquisa.

TILL, J.; SCHNEIDER, T. Flexible Housing: the means to the end. Theory, v. 9, n. 3/4, p. 287-296, 2005.

TILlMANn, P. A. Diretrizes Para a Adoção da Customização em Massa na Construção Habitacional Para Baixa Renda. 2008. Porto Alegre. Dissertação (Mestrado em Engenharia) Escola de Engenharia, Universidade Federal do Rio Grande do Sul, Porto Alegre, 2008.
TRAMONTANO, M. C. Espaços Domésticos Flexíveis: notas sobre a produção da primeira geração de modernistas brasileiros. São Paulo: FAU/USP, 1993. 15 p. Texto técnico.

VILLÀ, J. Flexibilidade: exigência do habitat contemporâneo. In: COLÓQUIO DE PESQUISAS EM HABITAÇÃO, 4., 2007, Belo Horizonte.

Anais... Belo Horizonte: EAUFMG, Grupo Morar de Outras Maneiras, 2007.

VILLA, S. B.; SILVA, M. C. V. Hab[A]:

elaboração e construção de uma unidade habitacional de baixo custo sob à ótica da flexibilidade. In: SEMINÁRIO MATOGROSSENSE DE HABITAÇÃO DE INTERESSE SOCIAL, 2005, Cuiabá. Anais... Cuiabá: CEFETMT, EdUFMT, 2005. 1 CD-ROM, p. 239-248.

\section{Agradecimentos}

À FINEP - Financiadora de Estudos e Pesquisas. Aos colegas pesquisadores da UFMT e do IFMT (antigo CEFETMT). À Professora Dra. Carolina Palermo, da Universidade Federal de Santa Catarina e à Arquiteta M.Sc. Mariuzza Digiacomo, da Caixa Econômica Federal.

Revista Ambiente Construído

Associação Nacional de Tecnologia do Ambiente Construído

Av. Osvaldo Aranha, $99-3^{\circ}$ andar, Centro

Porto Alegre - RS - Brasil

CEP $90035-190$

Telefone: +55 (51) 3308-4084

Fax: +55 (51) 3308-4054

www.seer.ufrgs.br/ambienteconstruido

E-mail: ambienteconstruido@ufrgs.br

96 Brandão, D. Q. 